\title{
WestVirginiaUniversity
}

THE RESEARCH REPOSITORY @ WVU

Graduate Theses, Dissertations, and Problem Reports

2020

\section{Injury-related infant mortality in West Virginia, 2010-2014}

Wilson A. Koech

West Virginia University

Follow this and additional works at: https://researchrepository.wvu.edu/etd

Part of the Epidemiology Commons, and the Maternal and Child Health Commons

\section{Recommended Citation}

Koech, Wilson A., "Injury-related infant mortality in West Virginia, 2010-2014" (2020). Graduate Theses, Dissertations, and Problem Reports. 7550.

https://researchrepository.wvu.edu/etd/7550

This Dissertation is protected by copyright and/or related rights. It has been brought to you by the The Research Repository @ WVU with permission from the rights-holder(s). You are free to use this Dissertation in any way that is permitted by the copyright and related rights legislation that applies to your use. For other uses you must obtain permission from the rights-holder(s) directly, unless additional rights are indicated by a Creative Commons license in the record and/ or on the work itself. This Dissertation has been accepted for inclusion in WVU Graduate Theses, Dissertations, and Problem Reports collection by an authorized administrator of The Research Repository @ WVU.

For more information, please contact researchrepository@mail.wvu.edu. 
Graduate Theses, Dissertations, and Problem Reports

2020

Injury-related infant mortality in West Virginia, 2010-2014

Wilson A. Koech

Follow this and additional works at: https://researchrepository.wvu.edu/etd

Part of the Epidemiology Commons, and the Maternal and Child Health Commons 


\title{
Injury-related infant mortality in West Virginia, 2010-2014
}

\author{
Wilson Arusei Koech \\ Dissertation submitted \\ to the School of Public Health \\ at West Virginia University \\ in partial fulfillment of the requirements for the degree of \\ Doctor of Philosophy \\ in \\ Epidemiology
}

\author{
Thomas C. Hulsey, Sc.D., M.S.P.H., Chair \\ Ian R. H. Rockett, Ph.D., M.P.H., Research Mentor \\ Christa L. Lilly, Ph.D., M.S. \\ Sijin Wen, Ph.D., M.S., M.A. \\ Department of Epidemiology \\ Morgantown, West Virginia \\ 2020
}

Keywords: Unintentional injury-related infant mortality, infant mortality, injury-related infant death

Copyright 2020 Wilson A. Koech 


\title{
Abstract \\ Injury-related infant mortality in West Virginia, 2010-2014
}

\author{
Wilson Arusei Koech
}

\section{Background and objective}

Infant mortality in United States is high relative to other more developed nations. Therefore, there is a need to curb this trend, especially in states with high infant mortality rates. Hence, this research investigated and examined characteristics associated with injury-related infant death in West Virginia. The objective of this retrospective study was to 1) investigate maternal and infant characteristics associated with injury-related infant deaths in West Virginia, 2) examine the relationship between unintentional-injury-related infant death and rurality in West Virginia, holding other variables in the model constant, and 3) compare differences in the unintentionalinjury related infant mortality rate between West Virginia and the United States as a whole, stratified by race/ethnicity.

\section{Methods}

De-identified linked birth-infant death data for the period 2010-2014 were sourced from the West Virginia Bureau for Public Health, Charleston WV and the United States linked birth-death vital records from the Centers for Disease Control website. Additionally, 2013 Urban Influence Codes used for urban/rural classification were sourced from the United States Department of Agriculture Economic Research Service.

A generalized linear model with binomial distribution was used to determine characteristics associated with injury-related infant death, and a generalized linear mixed model with binomial distribution was used to determine the relationship between unintentional injury-injury related infant death and rurality, holding other variables in the model constant. A non-model-based method, which follows a simple Poisson distribution, was used to calculate the infant mortality rate in West Virginia and the United States, stratified by race.

\section{Results}

Maternal characteristics associated with injury-related infant mortality in West Virginia were race/ethnicity $\left(\mathrm{X}_{\mathrm{df}=2}^{2}=7.48, \mathrm{p}=.03\right)$ and smoking during pregnancy $\left(\mathrm{X}_{\mathrm{df}=1}^{2}=13.1, \mathrm{p}<.00\right)$. Risk of a Non-Hispanic Black infant for an injury-related death was 4.0 (95\% CI: 1.7 - 9.3) times that of infants of other race/ethnicities. Unintentional injury-relate infant death was significantly associated with rurality, race/ethnicity and a rurality-smoking during pregnancy interaction $(\mathrm{p}=0.02, \mathrm{p}=0.3$, and $\mathrm{p}=0.05$ respectively). The relative risk for unintentional injury-related infant death in rural versus urban counties was 1.7 (95\% CI: 0.7- 3.8), whereas the unintentional injuryrelated infant mortality rate for West Virginia and the United States Non-Hispanic Black population was 83.2 (95\% CI: 26.8 - 258.0) deaths per 100,000 live births and 57.5 (95\% CI: 54.8 - 60.3) deaths per 100,000 live births, respectively. 


\section{Conclusion}

Injury-related infant mortality is associated with race/ethnicity and smoking during pregnancy. Smoking during pregnancy and living in rural counties was related to higher risk of unintentional injury-related infant death than living in urban counties, whether or not the mother smoked during pregnancy. In general, the unintentional injury-related infant mortality rate in West Virginia and the nation are similar.

Findings should be interpreted with caution due to the small number of cases. Nevertheless, this study provides important information to public health stakeholders, at both the state and local levels, for designing interventions for reduction or prevention of injury-related infant mortality in West Virginia. 


\section{Dedication}

I am greatly indebted to my family, work colleagues, and friends. Without their support, I would have never been able to complete my dissertation. Especially to my wife June and our wonderful children Kiptai and Jeptoo, I dedicate this work to you. Your boundless support, encouragement and love during my graduate school life has been a source of strength.

To my mother-in-law Sophie, I am truly thankful. You always fly over continents to help us, and without your support, I would not have completed this work. I also dedicate this dissertation to my mother, Martha Cheres. Your support and unconditional love have sustained me throughout my life. Thank you for teaching me the value of education. To my brothers and sisters too, thank you for your endless support. 


\section{Acknowledgments}

I would like to thank all the committee members for their guidance, mentorship and for agreeing to serve as my dissertation committee members. Much thanks and sincere gratitude to my research mentor Dr. Ian Rockett for your guidance and encouragement to this research topic and throughout my doctoral study. Thanks to my dissertation chair, Dr Thomas Hulsey, for your encouragement and assistance to overcome all the challenges throughout the $\mathrm{PhD}$ program. Thanks also to Dr. Christa Lilly. Your constant encouragement gave me the strength to push through all the challenges, both professionally and personally.

To Dr. Sijin Wen and Dr. Toni Rudisill, thank you for your constant words of wisdom and for support in this project. I am also grateful to Dr. Motao Zhu of Ohio State University. My transition from military to graduate school life was smooth because of your tireless effort in guiding and mentoring young scholars at the West Virginia University Injury Control Research Center. Lastly, I would like to acknowledge the West Virginia Bureau for Public Health in Charleston, West Virginia for providing data for this project. 


\section{Table of Contents}

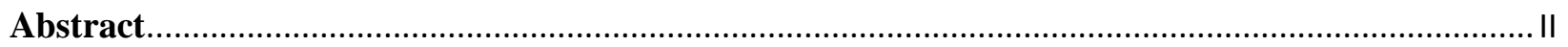

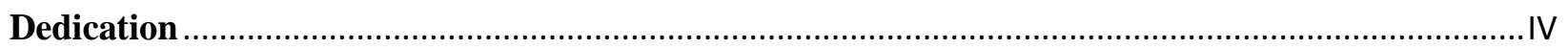

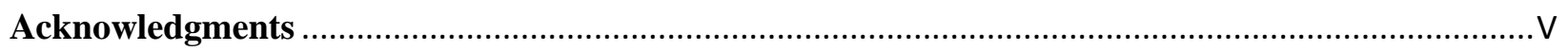

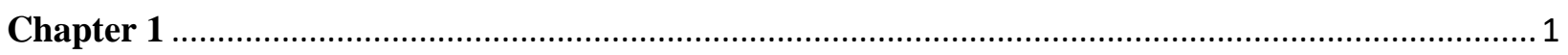

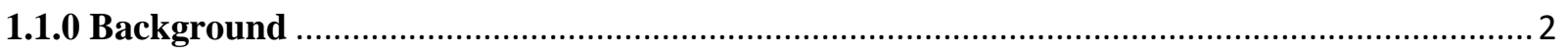

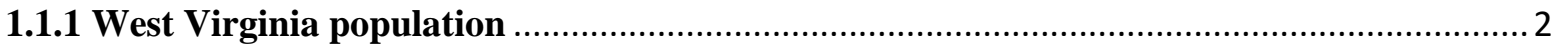

1.1.2 Risk factors of injury-related deaths........................................................................... 3

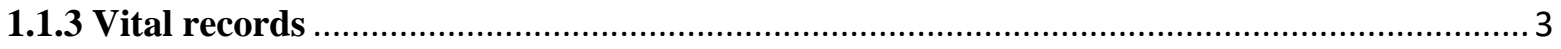

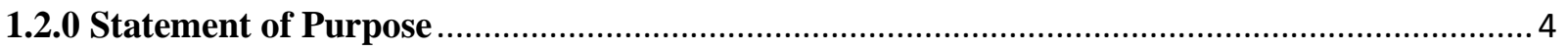

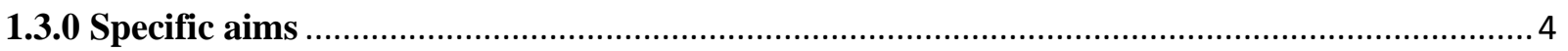

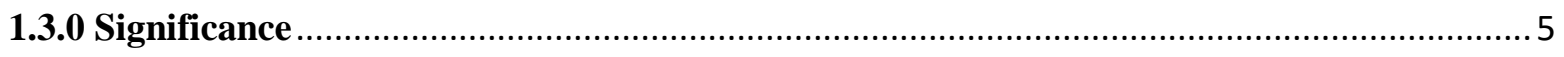

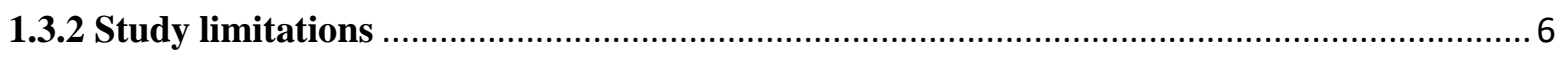

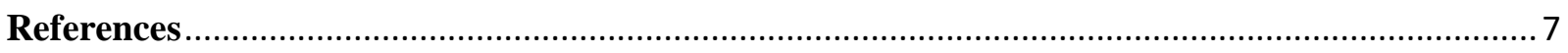

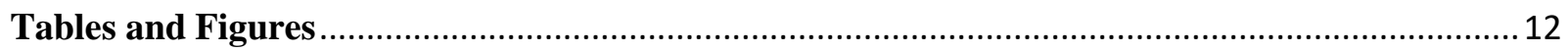

Table 1: International Classification of Disease, 10th revision codes by related-manner of infant

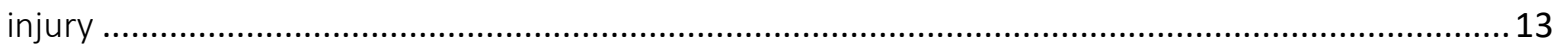

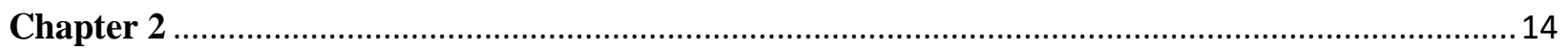

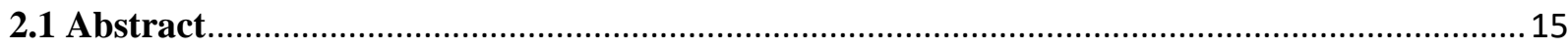

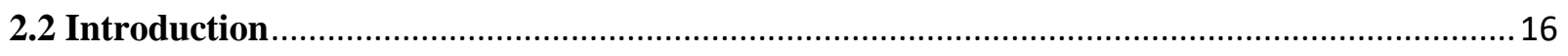

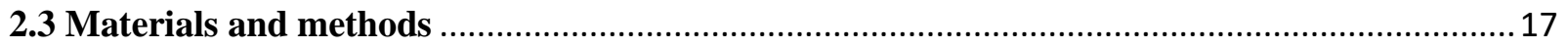

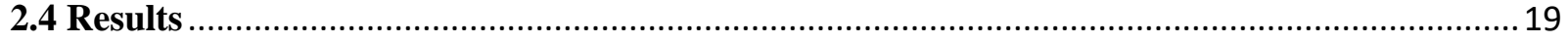

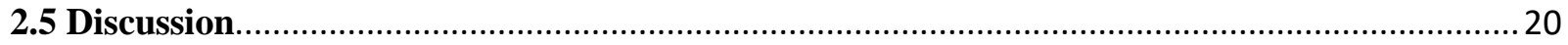

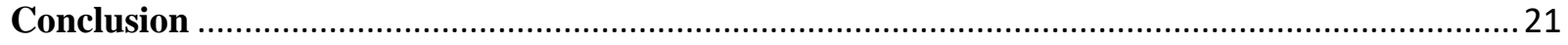

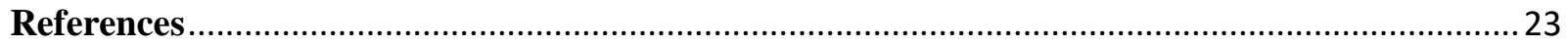

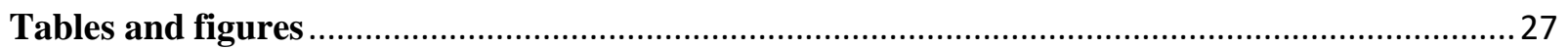

Table 1: Maternal and infant characteristics of West Virginia live births, 2010-2014, $n=102,683 \ldots .28$

Table 2: Relative risk for maternal characteristics associated with injury-related infant deaths, WV

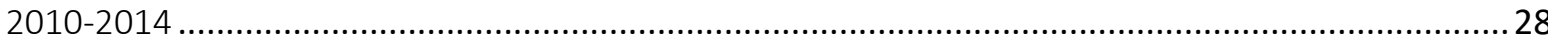

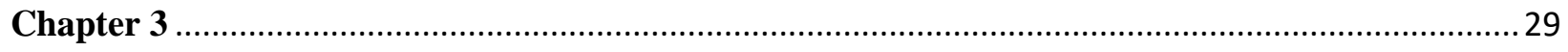

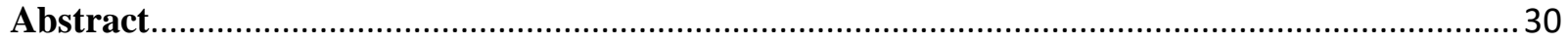

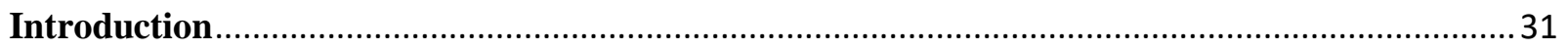

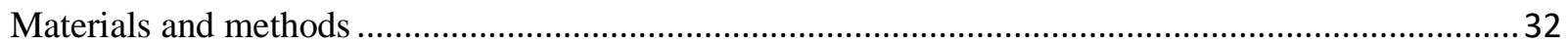




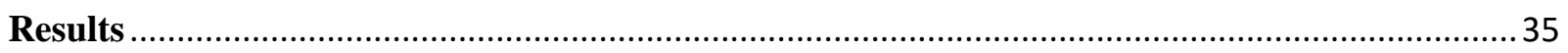

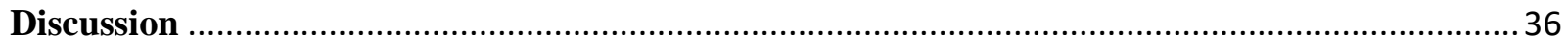

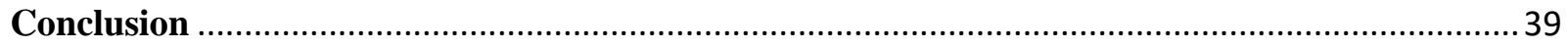

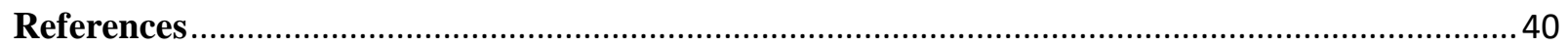

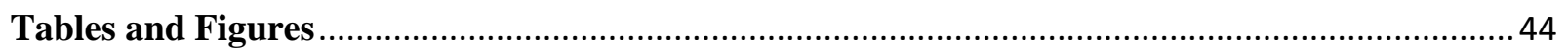

Table 1: Characteristics of unintentional injury-related infant deaths in West Virginia, 2010-2014.45

Table 2: Parameter estimates for unintentional injury-related infant deaths in West Virginia, 2010-

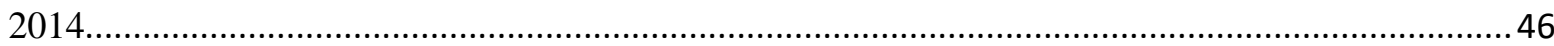

Table 3: Risks of unintentional injury-related infant deaths in selected characteristics, West Virginia

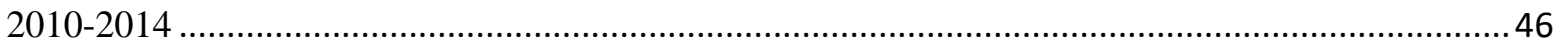

Figure 1: Rurality in West Virginia, 2010-2014 ................................................................... 47

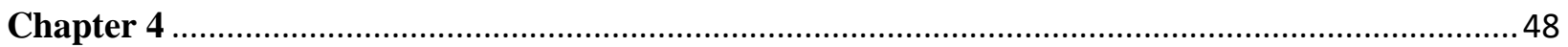

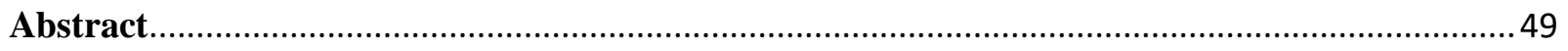

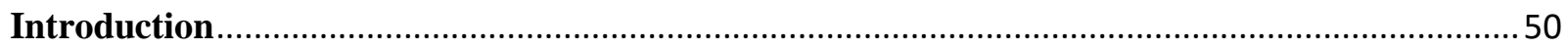

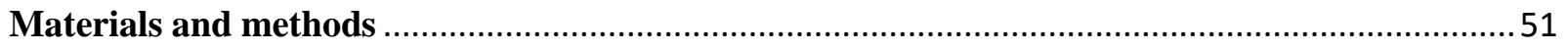

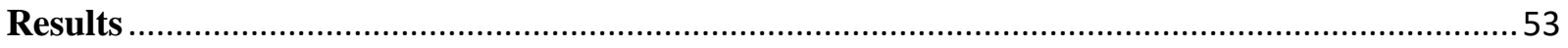

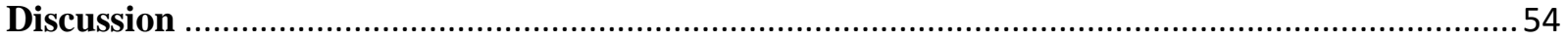

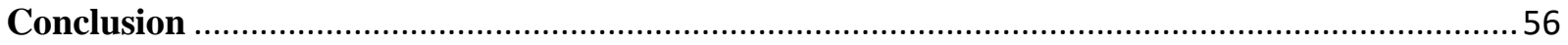

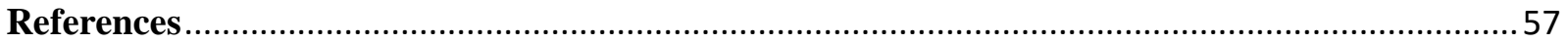

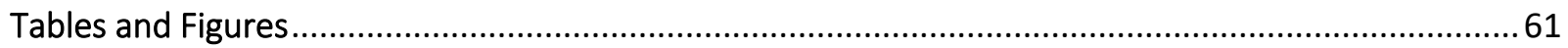

Table 1: Infant mortality in West Virginia and the United States, 2010-2014 ..................................62

Table 2: Unintentional injury-related infant mortality in West Virginia and the United States, 2010-

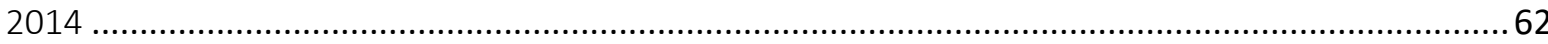

Figure 1: Related manner of injury-related infant deaths in West Virginia, 2010-2014....................63

Figure 2: Related manner of injury-related infant deaths in West Virginia, 2010-2014 ....................63

Figure 3: Related manner of injury-related infant deaths in West Virginia, 2010-2014....................64

Figure 4: Related manner of injury-related infant deaths in the United States, 2010-2014 ..............64

Figure 5: Related manner of injury-related infant deaths by intent in the United States, 2010-2014 65

Figure 6: Related manner of injury-related infant deaths in the United States, stratified by

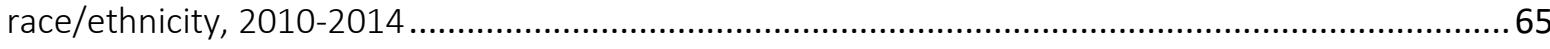

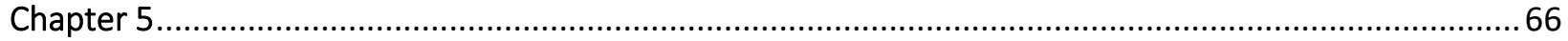

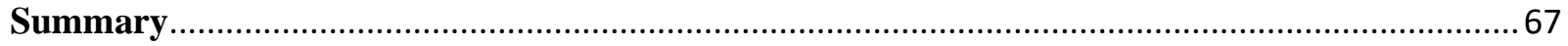

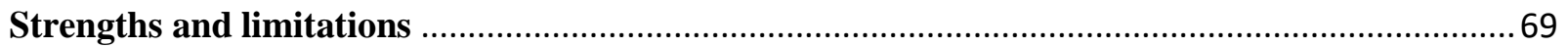

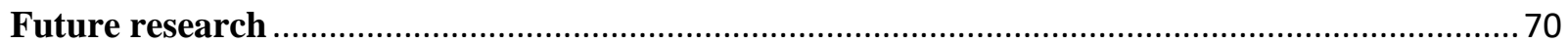


Conclusions.

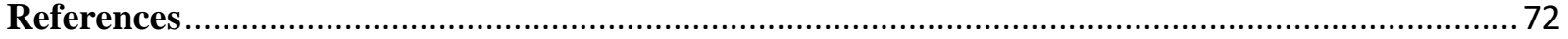


Chapter 1

Introduction 


\subsubsection{Background}

The World Health Organization's (WHO) 2030 sustainable development goal is to end preventable deaths by improving human health, especially for mothers and infants.[1] It is well documented that population health can be partially inferred from infant mortality.[2] According to the West Virginia Bureau for Public Health, the infant mortality rate (IMR) in 2010 was approximately 7.3 deaths per 1000 live births and 7.1 deaths per 1000 live births in 2014.[3] Not only is the IMR in West Virginia among the highest in the U.S, nearly $51 \%$ of West Virginia population reside in rural areas.[3,4] This is of particular concern as rurality is associated with preventable infant mortality.[2]

Another preventable death mechanism includes injury. Ballesteros and colleagues noted that injury and violence are associated with one child death every hour on average in the U.S.[5] Furthermore, there is a difference between the epidemiology and trends of injury-related deaths of children in urban and rural America. Children in rural areas are at a higher risk of dying from traumatic brain injury.[6] Therefore, we hypothesize that living in rural counties in West Virginia is associated with increased infant mortality. Ely and colleagues reported this relationship in their research on rurality and infant mortality in the United States (U.S).[2] Furthermore, prior research shows that the IMR in Appalachia is higher than the IMR in other parts of the country, and in addition, rural Appalachia registers a higher infant mortality rate compared to urban Appalachia.[7]

\subsubsection{West Virginia population}

West Virginia is the only state in the U.S. that is fully immersed in Appalachia and, according to the U.S. Census Bureau, approximately 0.9 million people and 1.0 million people lived in urban and rural areas, respectively in 2010. [4] During the 2010-2014 observation period, 101,121 live births were recorded in West Virginia.[3] 


\subsubsection{Risk factors of injury-related deaths}

Proximal and distal characteristics associated with infant mortality include maternal characteristics such as smoking, obesity, hypertension, and education.[8] Maternal smoking during pregnancy is associated with higher infant mortality, $[9,10]$ and rural areas are associated with higher risk of smoking compared to urban areas.[11,12] In addition, hypertension is associated with increased risk of premature birth and infant mortality, and obesity is associated with diabetes and hypertension, which is higher in rural areas than in urban areas.[13-15].[8] Moreover, caregiver and maternal education, a proxy measure for economic status, is associated with increased risk of infant mortality.[16] According to the U.S. National Center for Education Statistics (NCES), college enrolment is low among rural population.[17] Heerman and colleagues documented an association between caregiver education and non-adherence to injury prevention recommendations,[18] such as setting water heaters to an appropriate temperature, placing infants into an appropriate sleeping position, and management of firearm safety.[19] Other characteristics associated with injury-related infant deaths are lack of health insurance, healthcare access, prematurity, infant sex, birthweight, race/ethnicity and maternal age.[16,2023]

\subsubsection{Vital records}

The U.S. and West Virginia de-identified birth/death vital records are used in this study. Linked birth-death vital records for the 2010-2010 infant cohorts for the state were provided by the West Virginia Bureau for Public Health in Charleston, West Virginia, and the U.S link birthdeath infant cohorts for the same period were retrieved from the U.S Centers for Disease Control and Prevention (CDC) website.[3,24] These vital records data are not weighted for non-linked or missing records. 


\subsubsection{Statement of Purpose}

Knowledge of infant mortality is vital in understanding the socio-economic and health conditions of a community.[25] Hence, I further argue, in part, that reducing infant fatalities is vital for West Virginia's economic growth and health improvement. Herrick and colleagues note that lives can be saved when preventive medicine innovations are aimed at major determinants of mortality,[26] and some scholars consider non-proximal factors, such as rurality, are key avenues for reducing poor infant outcomes in the U.S.[27] Building on this research, this project investigates infant mortality in West Virginia by focusing on injury-related infant fatalities that can be partially or fully preventable. According to a British study, most infant injuries can be prevented, as can approximately three-quarters of neonatal deaths.[28]

Occurrences of infant deaths associated with preventable causes of death and plateauing of the IMR in the U.S. necessitates identification of new community-based methods for curbing infant mortality in West Virginia. Therefore, the overall objective of this project is to investigate injury-related infant mortality in West Virginia. The first aim of this research is to determine maternal and infant characteristics associated with injury-related infant death in West Virginia for the period 2010-2014. The second aim is to determine the relationship between rurality and unintentional injury-related infant deaths in West Virginia for the same observation period, and the third aim is to compare unintentional injury-related infant mortality rate in West Virginia and the U.S. This study is the first to investigate injury-related infant death in West Virginia.

The following three specific aims are investigated in-depth in chapters 2-to-4.

\subsubsection{Specific aims}

The first specific aim will be addressed in chapter 2. Its focus is the determination of maternal and infant characteristics associated with injury-related infant death. The hypothesis is that maternal and infant characteristics are associated with injury-related infant death, adjusted 
for other variables in the model. Chapter three addresses the second specific aim, which examines the question of whether unintentional-injury related infant death is significantly higher in rural counties than in urban counties. The hypothesis is that the relative risk of an unintentional-injury related infant death is significantly higher in rural counties than in urban counties, holding other variables in the model constant. The third specific aim addresses the question of whether the unintentional-injury related infant mortality rate in West Virginia is

significantly higher than the national rate. The hypothesis is that the unintentional-injury related infant mortality rate in the state is significantly higher than the national unintentional-injury related infant mortality rate, stratified by race/ethnicity.

Injury-related infant death is classified according to the external cause of death by intent classification matrix proposed by the Centers for Disease Control and Prevention (CDC).[29] External cause of injury-related death by manner or intent is reported in Table 1.

\subsubsection{Significance}

Study findings will inform the extant medical literature as well as contribute additional health information for policymaking, resource allocation and potential community-based behavioral modification or intervention methodologies. Added information includes identification of maternal and infant characteristics associated with injury-related infant deaths in West Virginia, the relationship between rurality and unintentional injury-related infant deaths in West Virginia, and comparative data on the unintentional injury-related infant mortality for West Virginia and the nation. Identifying the association between rurality and unintentional injuryrelated infant mortality will be vital in documenting disparities in injury-related infant mortality across counties in West Virginia. 


\subsubsection{Study limitations}

Study limitations are 1) lack of generalizability of the results to other parts of the country due to the skewed racial/ethnic distribution in the study population;[30] 2) medical coding errors can induce misclassification in external causes of death, [31] as can complex forensic investigations.[32] Misclassification could either push the relative risk towards or away from the null; and 3). Information bias may also impact results because the data were originally collected for administrative purposes not epidemiologic research.[33] 


\section{References}

1. Brizuela V, Tuncalp O. Global initiatives in maternal and newborn health. Obstetric medicine. 2017;10(1):21-25.

2. Ely DM, Driscoll AK, Mathews TJ. Infant mortality rates in rural and urban areas in the United States, 2014. Center for Disease Control and Prevention;2017.

3. West Virginia Bureau for Public Health. West Virginia vital statistics, 2014. In:

Resources WVDoHaH, ed. Charleston, WV: West Virginia Department of Health and Human Resources, Bureau for Public Health, Health Statistics Center; 2016:184.

4. The United States Census Bureau. West Virginia: 2010 population and housing unit counts. The U.S. Census Bureau; 2012 2012. CPH-2-50.

5. Ballesteros MF, Williams DD, Mack KA, Simon TR, Sleet DA. The Epidemiology of Unintentional and Violence-Related Injury Morbidity and Mortality among Children and Adolescents in the United States. International journal of environmental research and public health. 2018;15(4).

6. Cheng P, Li R, Schwebel DC, Zhu M, Hu G. Traumatic brain injury mortality among U.S. children and adolescents ages 0-19years, 1999-2017. Journal of safety research. 2020;72:93-100.

7. The Appalachian Regional Commission. Health disparities in Appalachia. Washington, D.C. 20172017.

8. Goldenberg RL, Culhane JF, Iams JD, Romero R. Epidemiology and causes of preterm birth. Lancet. 2008;371(9606):75-84. 
9. Salihu HM, Wilson RE. Epidemiology of prenatal smoking and perinatal outcomes. Early human development. 2007;83(11):713-720.

10. Mitchell EA, Milerad J. Smoking and the sudden infant death syndrome. Reviews on environmental health. 2006;21(2):81-103.

11. Agunwamba AA, Kawachi I, Williams DR, Finney Rutten LJ, Wilson PM, Viswanath K. Mental Health, Racial Discrimination, and Tobacco Use Differences Across Rural-Urban California. The Journal of rural health : official journal of the American Rural Health Association and the National Rural Health Care Association. 2017;33(2):180-189.

12. Liu L, Edland S, Myers MG, Hofstetter CR, Al-Delaimy WK. Smoking prevalence in urban and rural populations: findings from California between 2001 and 2012. The American journal of drug and alcohol abuse. 2016;42(2):152-161.

13. Ganz ML, Wintfeld N, Li Q, Alas V, Langer J, Hammer M. The association of body mass index with the risk of type 2 diabetes: a case-control study nested in an electronic health records system in the United States. Diabetology \& metabolic syndrome. 2014;6(1):50.

14. Jeyabalan A. Epidemiology of preeclampsia: impact of obesity. Nutrition reviews. 2013;71 Suppl 1:S18-25.

15. Cohen SA, Cook SK, Kelley L, Foutz JD, Sando TA. A Closer Look at Rural-Urban Health Disparities: Associations Between Obesity and Rurality Vary by Geospatial and Sociodemographic Factors. The Journal of rural health : official journal of the American Rural Health Association and the National Rural Health Care Association. 2017;33(2):167-179. 
16. Gage TB, Fang F, O'Neill E, Dirienzo G. Maternal education, birth weight, and infant mortality in the United States. Demography. 2013;50(2):615-635.

17. Provasnik S, KewalRamani A, Coleman M, Gilbertson L, Herring W, Xie Q. Status of education in rural America. Washington, D.C.: The United States Department of Education;2007.

18. Heerman WJ, Perrin EM, Sanders LM, et al. Racial and Ethnic Differences in Injury Prevention Behaviors Among Caregivers of Infants. American journal of preventive medicine. 2016;51(4):411-418.

19. Heerman WJ, Perrin EM, Yin HS, et al. Health literacy and injury prevention behaviors among caregivers of infants. American journal of preventive medicine. 2014;46(5):449456.

20. Xaverius P, Alman C, Holtz L, Yarber L. Risk Factors Associated with Very Low Birth Weight in a Large Urban Area, Stratified by Adequacy of Prenatal Care. Maternal and child health journal. 2016;20(3):623-629.

21. Devoe JE, Baez A, Angier H, Krois L, Edlund C, Carney PA. Insurance + access not equal to health care: typology of barriers to health care access for low-income families. Ann Fam Med. 2007;5(6):511-518.

22. DeVoe JE, Krois L, Stenger R. Do children in rural areas still have different access to health care? Results from a statewide survey of Oregon's food stamp population. The Journal of rural health : official journal of the American Rural Health Association and the National Rural Health Care Association. 2009;25(1):1-7. 
23. Johnelle Sparks P. One size does not fit all: an examination of low birthweight disparities among a diverse set of racial/ethnic groups. Maternal and child health journal. 2009;13(6):769-779.

24. Period linked birth-infant death data files 2010-2014. Centers for Disease Control and Prevention; 2018. https://www.cdc.gov/nchs/data_access/vitalstatsonline.htm\#Period_Linked. Accessed July $24,2018$.

25. Kim D, Saada A. The social determinants of infant mortality and birth outcomes in Western developed nations: a cross-country systematic review. International journal of environmental research and public health. 2013;10(6):2296-2335.

26. Herrick T, Harner-Jay C, Shaffer C, Zwisler G, Digre P, Batson A. Modeling the potential impact of emerging innovations on achievement of Sustainable Development Goals related to maternal, newborn, and child health. Cost effectiveness and resource allocation : C/E. 2017;15:12.

27. Mohamoud YA, Kirby RS, Ehrenthal DB. Poverty, urban-rural classification and term infant mortality: a population-based multilevel analysis. BMC pregnancy and childbirth. 2019;19(1):40.

28. Wise J. Most deaths of babies and brain injuries in childbirth are avoidable, says college. Bmj. 2017;357:j2989.

29. Annest J, Hedegaard H, Chen L, Warner M, Small E. Proposed Framework for Presenting Injury Data using ICD-10-CM External Cause of Injury Codes. National health statistics reports. 2014:1-32. 
30. The United States Cancer Statistics. National Center for Health Statistics staff manual on confidentiality. 2004; 27. Available at:

https://www.cdc.gov/cancer/uscs/technical_notes/stat_methods/suppression.htm.

Accessed December 18, 2018.

31. McGivern L, Shulman L, Carney JK, Shapiro S, Bundock E. Death Certification Errors and the Effect on Mortality Statistics. Public health reports. 2017;132(6):669-675.

32. Byard RW, Shipstone RA, Young J. Continuing major inconsistencies in the classification of unexpected infant deaths. J Forensic Leg Med. 2019;64:20-22.

33. Northam S, Knapp TR. The reliability and validity of birth certificates. Journal of obstetric, gynecologic, and neonatal nursing : JOGNN. 2006;35(1):3-12. 
Tables and Figures 
Table 1: International Classification of Disease, 10th revision codes by related-manner of infant injury

\begin{tabular}{lc}
\hline Manner & $\begin{array}{c}\text { International Classification of Diseases, 10th } \\
\text { revision Codes }\end{array}$ \\
\hline Accidental/unintentional & V01-X59, Y85-Y86 \\
Homicide & X85-Y09, Y87.01, 87.02, Y87.1 \\
Undetermined & Y10-Y34, Y87.2, Y89.9 \\
Legal intervention/war & Y35, Y36, Y89.0, Y89.1 \\
\hline
\end{tabular}


Chapter 2

Maternal characteristics associated with injury-related infant death in West Virginia,

2010-2014 


\subsection{Abstract}

\section{Objective}

The objective of this retrospective study was to investigate maternal and infant characteristics associated with injury-related infant deaths in West Virginia.

\section{Methods}

Birth and infant mortality data for 2010-2014 were sourced from the West Virginia Bureau for

Public Health, Charleston. Relative risk was calculated using log-binomial regression utilizing generalized estimating equations.

\section{Results}

Maternal characteristics associated with injury-related infant mortality in West Virginia were race/ethnicity $\left(\mathrm{X}_{\mathrm{df}=2}^{2}=7.48, \mathrm{p}=.03\right)$ and smoking during pregnancy $\left(\mathrm{X}_{\mathrm{df}=1}^{2}=13.1, \mathrm{p}<\right.$ .00). Risk of a Non-Hispanic Black infant suffering an injury-related death was 4.0 (95\% CL 1.7, 9.3) times that of infants of other races/ethnicities. Risk of an infant dying from an injury-related cause, if the mother smoked during pregnancy, was 2.9 (95\% CL 1.6, 5.0) times the risk of such a death if maternal smoking status during pregnancy is unknown or no smoking, adjusting for race/ethnicity.

\section{Conclusion}

Black (non-Hispanic) infants and infants of women reporting smoking during pregnancy have higher odds of injury-related death. This study provides important information to public health stakeholders at both the state and local levels in designing interventions for partial reduction or prevention of injury-related infant mortality in West Virginia. 


\subsection{Introduction}

Unintentional injury deaths and homicides impact children across all ages in the United States (U.S).[1-3] Although the unintentional injury-related death rate among children aged 19 years or younger declined by $29 \%$ from 2000 to 2009 nationally, the corresponding unintentional injury-related infant mortality rate rose approximately 20\%.[4] The smallest decline in the unintentional injury-related infant death rate was observed among the Black population (-21\%). Between 1999 and 2004, the national unintentional injury death rate increased by 7\%.[5] For the period 2000-2009, there was an annualized national rate of 1,081 infant deaths per 100,000 population.[6] Overall child mortality during this period in the U.S was 11,561 children deaths per 100,000 population, whereas the rate for West Virginia was 597 per 100,000.[6]

Overall, the rate of both unintentional and intentional injury-related deaths rose by $10 \%$ between 2000 and 2009 in the U.S. During the same period, children aged 0-4 years registered an injury-related death rate of 18.3 deaths per 100,000 population.[7] By 2014, unintentional injury was the fifth leading cause of infant mortality in the U.S,[8,9] and the fourth leading cause in West Virginia.[10]

Known risk factors associated with injury-related infant mortality include unhealthy behaviors associated with financial hardship, parental/caregiver behavior, and birth order.[11-14] A study based on California's metropolitan areas showed an increase in the unemployment rate of $1 \%$ was associated with an increase of $8 \%$ in the unintentional injury-related infant mortality rate.[12] Parental behaviors, such as inappropriate child car-seat placement, are associated with increased risk of unintentional injury-related infant mortality in the U.S.[12] Similarly, caregiver behavior, such as non-adherence to infant injury prevention recommendations (e.g., not having infants sleep in the prone position or leaving an infant unattended on a raised surface), is associated with elevated risk.[13] Head injuries are frequent among children involved in motor 
vehicle crashes, irrespective of age.[11] During the 2003-2013 period, unintentional injuries increased by $11 \%,[15]$ and Black infants were two to three times more likely to die from all injury, unintentional injury and homicide compared to White infants..[16] In the U.S., non-first born children have an increased risk of injury-related death.[14]

Even though high rates of injury-related infant mortality are being observed in the U.S and in West Virginia, insufficient attention is currently being directed towards prevention efforts in West Virginia,' Yet injury-related infant deaths might be partially or completely prevented. The focus of this study was maternal and infant characteristics associated with injury-related infant deaths in West Virginia, adjusted for race/ethnicity. Understanding maternal and infant characteristics associated with injury-related infant deaths could inform public health stakeholders on potential interventions that could partially prevent such deaths in West Virginia; an extremely poor state and the only state in the U.S. fully immersed in Appalachia. The Appalachian region is characterized by poor access to healthcare, low income, and high rates of unemployment and high poverty.[17]

\subsection{Materials and methods}

Data source. The primary data source for this analysis was birth and death records obtained from the West Virginia Bureau for Public Health, Charleston. The West Virginia University Institutional Review Board approved the parent study.

Dependent variable. The study outcome was a binary variable called injury-related infant deaths $(0=$ alive, $1=$ died $)$. Injury-related infant deaths were constructed from external causes of mortality, building on the Centers for Disease Control and Prevention (CDC) injury classification matrix.[18] In this matrix, injury-related infant deaths disaggregated by manner of injury are: 1) accidents by cutting/piercing, drowning, fall, fire/hot object or substance, firearm, machinery, and transport; 2) homicides by cutting/piercing, drowning, fall, fire/hot object or 
substance, firearm, and transport; 3) other (legal intervention/war, and undetermined). Therefore, the outcome variable encompasses infant deaths by manner of injury, categorized by ICD-10 revision codes V01-X59, Y85-Y86, X85-Y09, Y87.01, 87.02, Y87.1, Y10-Y34, Y87.2, Y89.9, Y35, Y36, Y89.0, and Y89.1. Excluded were infant deaths associated with other causes.

Independent variables. Explanatory variables included both categorical and continuous variables. These variables were: 1) maternal demographic, health, and behaviorial characteristics, including education (greater than high school, high school/GED or less), insurance type/payer (Medicaid, Non-Medicaid and unknown), smoking during pregnancy (yes, no, unknown), age, race-ethnicity (Non-Hispanic Black, other races/ethnicities), pregnancy term (preterm, term or post-term), trimester primary care began (first, second, third, no care), gestational diabetes (yes, no) and gestational hypertension (yes, no); and 2) newborn characteristics, including birth year, sex, and birthweight.

Statistical analysis. Statistical analysis employed both descriptive and inferential statistics. Among descriptive statistics captured were proportions, mean, and spread of variables. Statistical investigation covered variable correlation analysis using Kendell correlation and multicollinearity.

In inferential statistics, maternal and infant characteristics associated with injury-related deaths, as well as risk of injury-related mortality, were investigated. Relative risk was calculated using log-binomial regression utilizing generalized estimating equations (GEE).[19] Bivariable analysis was conducted, and main effects with $\mathrm{p}>0.15$ were included in the model. Thereafter, a parsimonious model was developed and compared with an intercept-only model using Akaike's Information Criterion (AIC). Two-way interaction effects for all variables were considered. In 
addition, model fitness was investigated Likewise, Wald chi-square statistics and associated $95 \%$ confidence limits were reported.

Data management and analysis were conducted using SAS/STAT software, version 9.4 of the SAS systems for windows. Copyright ${ }^{\circledR}$ 2002-2012 by SAS Institute Inc., Cary, NC, USA.[20]

\subsection{Results}

The West Virginia live birth distribution for the period 2010-2014 by race/ethnicity was 93.6\% White (non-Hispanic), 3.5\% Black (non-Hispanic), and 2.9\% other races/ethnicities. A majority of injury-related infant deaths was White. When infant deaths were stratified by form of payment, during the perinatal period, $41 \%$ of women utilized the Medicaid insurance program. Stratifying by maternal smoking during pregnancy, $49 \%$ of the infant deaths were to women who smoked during pregnancy (Table 1).

Investigation of explanatory variable correlation was implemented using the Kendell correlation, and multicollinearity was assessed using the variance inflation factor (data not shown). A bivariable binomial regression analysis was executed to identify significant main effects used in developing a fully parameterized model. Significant main effects in the bivariable regression analysis were race/ethnicity $(\mathrm{p}=.0311)$, smoking during pregnancy (.0006), and insurance status $(\mathrm{p}=.1198)$.

Significant main effects in the multivariable log-binomial regression model using GEE were race/ethnicity, $\mathrm{X}_{\mathrm{df}=2}^{2}=7.48, \mathrm{p}=.0276$ and smoking during pregnancy, $\mathrm{X}_{\mathrm{df}=1}^{2}=13.1, \mathrm{p}=$ .0003. See Table 2 for more details. Overdispersion was assessed using model deviance, and model fitness was assessed using AIC. The intercept only model AIC was 846.1, and the parsimonious model AIC was 26.6, meaning the parsimonious model provided better predictive power than the intercept only model.[21] 
The risk of a Black infant dying from injury-related causes was 4.0 (95\% CL 1.7, 9.3) times the risk for infants from other races/ethnicities, given that the other variables in the model are held constant. However, the risk of an infant dying from injury-related causes, if the mother smoked during pregnancy, was $2.9(95 \%$ CL 1.6, 5.0) times the risk if smoking status was unknown or the mother did not smoke, holding other variables in the model constant (Table 2).

\subsection{Discussion}

This study evaluated maternal and infant characteristics associated with injury-related infant death in West Virginia. Race/ethnicity and smoking during pregnancy were significantly associated with injury-related infant deaths. Similar findings of racial/ethnic disparity in injuryrelated deaths is documented by Khan and colleagues and Ahrens and colleagues.[3,14] Such differences in injury-related infant deaths might be explained by racial/ethnic disparities in healthcare access and utilization. Past studies showed that Non-Hispanic Blacks were more likely than White Non-Hispanic counterparts to receive low-quality healthcare and to have higher risk of hospital death after injury.[16,22] Racial/ethnic disparities in injury-related infant deaths highlight the need for tailored intervention strategies that will improve healthcare access at state and local levels.

Smoking during pregnancy was significantly associated with injury-related infant mortality. This variable might be a proxy for capturing characteristics known to be associated with injury-related deaths, such as infant maltreatment.[23] Cigarette smoking has been associated with drug abuse.[24] Therefore, smoking during pregnancy might be a proxy for substance abuse, a risk factor for child neglect and maltreatment.[25] It was expected to be a statistically significant risk factor for infant mortality because child neglect and maltreatment are associated with drug abuse.[24,25] 
Insurance status in the perinatal period was an important maternal characteristic to investigate. Although not statistically significant in the multivariable analysis, it was in the bivariable analysis $(\mathrm{p}=0.0566)$, thus warranting further investigation using balanced racial/ethnic populations, since socio-economic disparities are associated with injury-related deaths by manner.[26]

Study limitations include few cases of injury-related deaths and skewedness in racial/ethnic distribution. Over $90 \%$ of the population in West Virginia are Non-Hispanic White hence injury-related deaths from other races/ethnicities was small. Addition, infant deaths associated with causes death other than external cause of death were deleted, therefore the reported injury-related infant death count was small. Small numbers of cases can destabilize statistical models. Therefore, findings from this study should be interpreted with caution. Detailed presentation of descriptive statistics, such as injury-related infant mortality rates, could not be presented. The Centers for Disease Control and Prevention (CDC) opposes publication of sample size, cell sizes or mortality rates involving fewer than ten cases.[27] The reliability of vital records might be also be problematic due to case misclassification. Past research documents sources of errors in medical records collected for purposes other than research.[28] Finally, variables collected in vital records are limited, hence yielding fewer options for statistical model building. In addition, no paternal characteristics are collected during pregnancy, thus the study might be missing other important information.

\section{Conclusion}

Black (non-Hispanic) infants have higher odds of experiencing injury-related death compared to infants of other races/ethnicities in West Virginia. Furthermore, infants of women reporting smoking during pregnancy have higher odds of injury-related death than those of women who reported not smoking or whose smoking status was unknown. 
This study provides important information to public health stakeholders at both state and local levels. Study implications include formulating community-based intervention strategies to protect at-risk populations from loss of years of life associated with injury-related infant mortality. Future research should investigate the association of all household characteristics and injury-related infant deaths. This study could only access maternal and infant characteristics, and paternal characteristics might provide additional information. 


\section{References}

1. Fowler KA, Dahlberg LL, Haileyesus T, Gutierrez C, Bacon S. Childhood Firearm Injuries in the United States. Pediatrics. 2017;140(1).

2. Jain A, Khoshnood B, Lee KS, Concato J. Injury related infant death: the impact of race and birth weight. Injury prevention : journal of the International Society for Child and Adolescent Injury Prevention. 2001;7(2):135-140.

3. Khan SQ, Berrington de Gonzalez A, Best AF, et al. Infant and Youth Mortality Trends by Race/Ethnicity and Cause of Death in the United States. JAMA pediatrics. 2018;172(12):e183317.

4. Centers for Disease Control and Prevention. Vital signs: Unintentional injury deaths among persons aged 0-19 years - United States, 2000-2009. MMWR Morbidity and mortality weekly report. 2012;61:270-276.

5. Centers for Disease Control and Prevention. State-specific unintentional-injury deaths-United States, 1999-2004. MMWR Morbidity and mortality weekly report. 2007;56(43):1137-1140.

6. Borse NN, Rudd RA, Dellinger AM, Sleet DA. Years of potential life lost from unintentional child and adolescent injuries--United States, 2000-2009. Journal of safety research. 2013;45:127-131.

7. Rockett IR, Regier MD, Kapusta ND, et al. Leading causes of unintentional and intentional injury mortality: United States, 2000-2009. American journal of public health. 2012;102(11):e84-92. 
8. Mathews TJ, Driscoll AK. Trends in Infant Mortality in the United States, 2005-2014. NCHS data brief. 2017(279):1-8.

9. Kochanek KD, Murphy SL, Xu J, Tejada-Vera B. Deaths: Final Data for 2014. National vital statistics reports : from the Centers for Disease Control and Prevention, National Center for Health Statistics, National Vital Statistics System. 2016;65(4):1-122.

10. West Virginia Bureau for Public Health. West Virginia vital statistics, 2014. In: Resources WVDoHaH, ed. Charleston, WV: West Virginia Department of Health and Human Resources, Bureau for Public Health, Health Statistics Center; 2016:184.

11. Arbogast KB, Wozniak S, Locey CM, Maltese MR, Zonfrillo MR. Head impact contact points for restrained child occupants. Traffic injury prevention. 2012;13(2):172-181.

12. Bruckner TA. Metropolitan economic decline and infant mortality due to unintentional injury. Accident; analysis and prevention. 2008;40(6):1797-1803.

13. Heerman WJ, Perrin EM, Sanders LM, et al. Racial and Ethnic Differences in Injury Prevention Behaviors Among Caregivers of Infants. American journal of preventive medicine. 2016;51(4):411-418.

14. Ahrens KA, Rossen LM, Thoma ME, Warner M, Simon AE. Birth Order and InjuryRelated Infant Mortality in the U.S. American journal of preventive medicine. 2017;53(4):412-420.

15. Mathews TJ, MacDorman MF, Thoma ME. Infant mortality statistics from the 2013 period linked birth/infant death data set. National vital statistics reports : from the Centers for Disease Control and Prevention, National Center for Health Statistics, National Vital Statistics System. 2015;64(9):1-30. 
16. Bernard SJ, Paulozzi LJ, Wallace DL, Centers for Disease C, Prevention. Fatal injuries among children by race and ethnicity--United States, 1999-2002. Morbidity and mortality weekly report Surveillance summaries. 2007;56(5):1-16.

17. Black DA, Sanders aSG. Labor market performance, poverty and income inequality in appalachia. Appalachian Regional Commission 2004.

18. Annest J, Hedegaard H, Chen L, Warner M, Small E. Proposed Framework for Presenting Injury Data using ICD-10-CM External Cause of Injury Codes. 2014:1-32.

19. McNutt LA, Wu C, Xue X, Hafner JP. Estimating the relative risk in cohort studies and clinical trials of common outcomes. American journal of epidemiology. 2003;157(10):940-943.

20. SAS Institute. SAS/STAT software SAS Institute Inc; 2012.

21. Rao CR, Wu Y. On model selection: IMS Lecture Notes - Monograph Series 2001;38.

22. Arthur M, Hedges JR, Newgard CD, Diggs BS, Mullins RJ. Racial disparities in mortality among adults hospitalized after injury. Medical care. 2008;46(2):192-199.

23. King AJ, Farst KJ, Jaeger MW, Onukwube JI, Robbins JM. Maltreatment-Related Emergency Department Visits Among Children 0 to 3 Years Old in the United States. Child maltreatment. 2015;20(3):151-161.

24. Lai S, Lai H, Page JB, McCoy CB. The association between cigarette smoking and drug abuse in the United States. Journal of addictive diseases. 2000;19(4):11-24.

25. Smith DK, Johnson AB, Pears KC, Fisher PA, DeGarmo DS. Child maltreatment and foster care: unpacking the effects of prenatal and postnatal parental substance use. Child maltreatment. 2007;12(2):150-160. 
26. Cubbin C, Smith GS. Socioeconomic inequalities in injury: critical issues in design and analysis. Annual review of public health. 2002;23:349-375.

27. The United States Cancer Statistics. National Center for Health Statistics staff manual on confidentiality. 2004; 27. Available at: https://www.cdc.gov/cancer/uscs/technical_notes/stat_methods/suppression.htm. Accessed December 18, 2018.

28. Northam S, Knapp TR. The reliability and validity of birth certificates. Journal of obstetric, gynecologic, and neonatal nursing : JOGNN. 2006;35(1):3-12. 
Tables and figures 
Table 1: Maternal and infant characteristics of West Virginia live births, 2010-2014, n = 102,683

\begin{tabular}{|c|c|c|c|}
\hline \multirow[b]{2}{*}{ Variable } & \multirow[b]{2}{*}{ Class } & \multirow{2}{*}{$\frac{\text { Died }}{\%^{*}}$} & \multirow{2}{*}{$\frac{\text { Alive }}{\% *}$} \\
\hline & & & \\
\hline \multirow[t]{3}{*}{ Race/ethnicity } & White Non-Hispanic & 86.0 & 93.6 \\
\hline & Non-Hispanic Black & 12.0 & 3.5 \\
\hline & Other & 2.0 & 2.9 \\
\hline \multirow[t]{2}{*}{ Pregnancy term } & Term \& Post-term & 88.0 & 89.3 \\
\hline & Preterm & 12.0 & 10.7 \\
\hline \multirow[t]{2}{*}{ Sex } & Male & 54.9 & 50.9 \\
\hline & Female & 45.1 & 49.1 \\
\hline \multirow[t]{2}{*}{ Prenatal Care } & Prenatal & 98.0 & 99.4 \\
\hline & No care & 2.0 & 0.6 \\
\hline \multirow[t]{2}{*}{ Insurance status } & Non-Medicaid or Unknown & 58.8 & 50.2 \\
\hline & Medicaid & 41.2 & 49.8 \\
\hline \multirow{2}{*}{ Smoked during pregnancy } & No or Unknown & 51.0 & 73.6 \\
\hline & Smoked & 49.0 & 26.4 \\
\hline \multirow[t]{2}{*}{ Maternal Education } & $\leq$ High School & 47.1 & 48.2 \\
\hline & $>$ High School & 52.9 & 51.8 \\
\hline \multirow[t]{2}{*}{ Gestational Hypertension } & No & 92.2 & 93.0 \\
\hline & Yes & 7.8 & 7.0 \\
\hline \multirow[t]{2}{*}{ Gestational Diabetes } & No & 98.0 & 95.6 \\
\hline & Yes & 2.0 & 4.4 \\
\hline \multirow[t]{3}{*}{ Maternal age-group } & $\leq 20$ years & 19.6 & 17.4 \\
\hline & 21-39 years & 78.4 & 81.3 \\
\hline & $\geq 40$ years & 2.0 & 1.3 \\
\hline
\end{tabular}

$*=$ Column percentage relative to variable class, totaling to $100 \%$ per variable

Data source: West Virginia Bureau for Public Health, Charleston, WV

Table 2: Relative risk for maternal characteristics associated with injury-related infant deaths, WV 2010-2014

\begin{tabular}{|c|c|c|c|c|c|c|}
\hline \multirow[b]{2}{*}{ Parameter } & \multirow[b]{2}{*}{ Class } & \multirow{2}{*}{$\begin{array}{l}\text { Relative } \\
\text { Risk }\end{array}$} & \multicolumn{2}{|c|}{$\begin{array}{c}\text { Relative Risk } \\
95 \% \text { CL* }\end{array}$} & \multirow[b]{2}{*}{$\mathbf{x}^{2}$} & \multirow[b]{2}{*}{ p-value } \\
\hline & & & Lower & Upper & & \\
\hline Race/ethnicity & Non-Hispanic Black & 4.0 & 1.7 & 9.3 & 10.1 & 0.0015 \\
\hline Smoked during pregnancy & Yes & 2.9 & 1.6 & 5.0 & 13.7 & 0.0002 \\
\hline \multicolumn{7}{|c|}{$\begin{array}{l}\text { Race/ethnicity = (Non-Hispanic Black, Other races/ethnicities }) \\
\text { Smoked during pregnancy = (Yes or No, and unknown) } \\
*=95 \text { percent confidence limits }\end{array}$} \\
\hline \multicolumn{7}{|c|}{ Data source: West Virginia Bureau for Public Health, Charleston, WV } \\
\hline
\end{tabular}


Chapter 3

Association between rurality and unintentional injury-related infant mortality in West

Virginia, 2010-2014 


\section{Abstract \\ Objective}

The objective of this retrospective study was to examine the association between rurality and the unintentional-injury-related infant death rate in West Virginia, holding other variables in the model constant.

\section{Methods}

Birth and infant mortality data for 2010-2014 were sourced from the West Virginia Bureau for Public Health, Charleston and 2013 Urban Influence Codes used for rural/urban classification were sourced from the U.S. Department of Agriculture Economic Research Service. Relative risk was based on a log-binomial distribution utilizing generalized linear mixed models.

\section{Results}

The unintentional injury-relate infant death rate was not significantly associated with rurality but was with the race/ethnicity by smoking during pregnancy interaction $(\mathrm{p}=0.09$ and $\mathrm{p}=0.00$ respectively). The relative risk for unintentional injury-related infant death in rural versus urban counties was 1.7 (95\% CI: 0.9 - 3.3) while maternal not smoking and unknown smoking status during pregnancy exposed infants to 0.3 (95\% CI: 0.2 - 0.8).times risk of injury-related death relative to their peers whose mothers smoked during pregnancy.

\section{Conclusion}

The unintentional injury-related death rate among infants was not correlated with rurality, but it was correlated with smoking during pregnancy. 


\section{Introduction}

Despite advancements in biomedical research, medical technology, and specialized medical treatments, the United States (U.S.) experiences a higher injury-related mortality rate than other more developed nations.[1,2] The association between rurality and infant mortality in the U.S. is well documented.[3] However, no studies have investigated the association between rurality and unintentional injury-related infant mortality in West Virginia, where approximately 51 percent of the population resided in rural counties in 2010.[4] Examination of potential disparities in unintentional injury-related infant deaths in urban and rural counties may inform the vital context for public health stakeholders, who are seeking to improve infant outcomes in West Virginia and other U.S. states or regions with large rural populations.

Some scholars attribute mortality differences to inequities in social determinants of health (e.g., education and poverty) rather than differential use of resources by urban and rural counties, [5] whereas others primarily consider non-proximal factors, such as rurality, as key avenues for reducing poor infant outcomes in the U.S.[6] Residents in metropolitan areas experienced greater mortality declines during the past four decades than non-metropolitan residents, contributing to a widening of the infant mortality rate gap.[7]

Factors associated with injury-related infant mortality include lack of health insurance, healthcare access barriers, low birth weight, African American race/ethnicity, premature birth, male sex, and infants of young unmarried mothers with low educational attainment.[8-12] Additionally, studies show that the infant mortality rate increases with rurality or smoking during pregnancy, $[3,13]$ and there is a likelihood that unintentional injury-related infant fatalities follow suit. Hence, the main objective of this study is to investigate the association between rurality and unintentional injury-related infant death in West Virginia, a state with a large rural population that is over-representative of several of the aforementioned risk factors. Understanding the 
relationship between rurality and unintentional injury-related infant mortality will be critical for transforming healthcare delivery and reducing the infant mortality rate.

Materials and methods

Data sources. Distal and proximal variables were incorporated in this study. Data were extracted from de-identified, linked birth/death vital records, for the period 2010 through 2014, from the West Virginia Bureau for Public Health in Charleston, West Virginia.[14] Urban Influence Codes included in records for 2013 from the U.S. Department of Agriculture (USDA) Economic Research Service were used to classify the relative urbanicity/rurality of West Virginia counties.[15] The West Virginia University Institutional Review Board (IRB) approved this study.

Dependent variable. Unintentional injury-related death was the dependent variable $(0=$ lived, $1=$ died). Thus, the outcome was binomial, with unintentional injury-related infant deaths classified according to the Centers for Disease Control and Prevention's (CDC) proposed classification matrix for external cause of death by manner of injury.[16] The International Classification of Diseases, tenth revision (ICD-10), codes used to classify unintentional injuryrelated infant deaths were V01-X59 and Y85-Y86. All other causes of infant death, infants with missing records for gestational weeks or birth weight, and women with unknown age were excluded from this research.

Main predictor. The main predictor was rurality $(0=$ urban counties, $1=$ rural counties $)$. West Virginia counties were classified as urban or rural using the 2013 rather than the 2003 Urban Influence Codes from the USDA. According to the U.S. Office of Management and Budget (OMB), these codes classify metropolitan counties by the population size of their metropolitan areas and classify nonmetropolitan counties by the population size of the largest city or town in each county and the county's proximity to metropolitan and micropolitan areas. 
Metropolitan categories are subdivided into two sub-categories and nonmetropolitan categories into ten sub-categories.[15] In this study, counties were classified into two categories in accordance with USDA classification: Urban counties were counties with the following population characteristics: 1) A large metropolitan area of one million or more residents, or 2) A small metropolitan area of less than 1 million residents. Rural counties were characterized as follows: 1) A micropolitan area adjacent to a large metropolitan area, or 2) noncore adjacent to a large metropolitan area, or 3) A micropolitan area adjacent to a small metropolitan area, or 4) Noncore adjacent to a small metropolitan area and contain a town of at least 2,500 residents, or 5) Noncore adjacent to a small metropolitan area and does not contain a town of at least 2,500 residents, or 6) Micropolitan area not adjacent to a metro area, or 7) Noncore adjacent to a micropolitan area and contains a town of at least 2,500 residents, or 8) Noncore adjacent to a micropolitan area and does not contain a town of at least 2,500 residents, or 9) Noncore not adjacent to metro or micro area and contains a town of at least 2,500 residents, or 10). Noncore not adjacent to a metropolitan or micropolitan area and does not contain a town of at least 2,500 residents. Figure 1 shows 2010-2014 rurality distribution in West Virginia, and it classified some counties that seem to be rural as urban counties, for instance Preston and Boone counties. This is because urban influence code classification scheme considers not only population density per square mile, but it also considers the proportion of people commuting from adjacent counties to work in urbanized area, thus capturing the economic and social integration of a counties.

Other independent variables. Explanatory variables included both distal and proximal factors. The single distal variable was rurality, a binary variable that classified each West Virginia county as rural or urban as previously described $(0=$ urban, $1=$ rural $)$. Proximal variables included maternal and infant factors, such as maternal education $(0=$ high school 
diploma/GED or less, 1 = any education beyond high school), maternal smoking during pregnancy $(0=$ did not smoke during pregnancy or unknown smoking status during pregnancy, 1 $=$ smoked during pregnancy), maternal age $(0=$ less than 21 years or over 39 years, $1=$ aged 21 39 years), insurance type/payer $(0=$ non Medicaid or unknown insurance status, $1=$ Medicaid insurance $)$, race/ethnicity $(0=$ other races/ethnicities, $1=$ Non-Hispanic Black $)$, birthweight $(0=$ less than 2500 grams, $1=$ equal or greater than 2500 grams $)$, maternal history of diabetes $(0=$ no history of diabetes, $1=$ history of diabetes $)$, maternal history of hypertension $(0=$ no history of hypertension, 1 = history of hypertension $)$, and infant sex $(0=$ male, $1=$ female $)$.

Statistical analysis. Descriptive and inferential statistical analyses are presented. Descriptive statistics included frequency distribution and measures of central tendency and spread, and inferential statistical investigation included a generalized linear mixed model (GLMM) to account for nesting.[17-19] To ascertain that no logistic regression assumptions were violated, GLMM with binomial distribution and logit link function were used in modeling.[17,18] Statistical investigation also included analysis of correlation using the Spearman correlation coefficient where applicable. Multicollinearity and influential observations were also considered.

An alpha level equal to or less than 0.2 was used to determine variables for inclusion in a fully parameterized model during multivariable binomial regression model building. Wald chisquare statistics and the deviance test were used for assessing statistically significant variables and model fitness, respectively. Additionally, relative risks and associated ninety five percent confidence limits (95\% CIs) were documented. Relative risks were calculated using GLMM logbinomial distribution. [20,21] The SAS/STAT software version 9.4, SAS Institute, Cary, NC was used in data management and analysis.[22] 


\section{Results}

The West Virginia Bureau of Public Health documented 103,424 live births during the 2010-2014 period. Mean age of birth mothers was 26 years. Half of the mothers used Medicaid insurance during pregnancy, and half had a high school education or less. White Non-Hispanic infants accounted for $93.5 \%$ of all live births.

A total of 102,540 live births was examined after excluding infants dying from causes other than an unintentional injury-related death, infants with missing records for gestational age or birth weight, and mothers of unknown age. Non-Hispanic Black infants accounted for approximately $3 \%$ of the live birth infant population and White Non-Hispanics accounted for 93.5\%. Approximately $62 \%$ of live births were classified as urban. Correlations between predictors ranged between -0.3 and 0.3 . During the 2010-2014 observation period, 15 infants died in rural counties and 14 in urban counties (Table 1).

Univariable GLMM with binomial distribution and logit link function indicated a significant $($ alpha $=0.25)$ association between unintentional injury-related infant death and the following variables: urbanicity $(\mathrm{p}=0.1334)$ and smoking during pregnancy $(\mathrm{p}=0.0375)$. Variables not significantly associated with unintentional injury-related infant death were race/ethnicity $(\mathrm{p}=0.3487)$, and birth weight $(0.2242)$, maternal age $(\mathrm{p}=0.4230)$, infant sex $(\mathrm{p}=0.7509)$, Medicaid insurance status $(\mathrm{p}=0.6911)$, maternal education $(\mathrm{p}=0.4709)$, maternal history of diabetes $(\mathrm{p}=0.7687)$, and maternal history of hypertension $(\mathrm{p}=0.9884)$.

Parameter coefficients for the intercept, urbanicity and smoking during pregnancy in fully parameterized GLMM were -6.1, - 21.7, and - 0.8, respectively. Rurality and its interaction with smoking during pregnancy in partially reduced GLMM had p-values equal to 0.0704 (Table 2), whereas parameter coefficients for variables in the parsimonious model were -7.8 (intercept), 0.6 (rurality, p-value $=0.0905)$ and -1.1 for smoking during pregnancy $($ Table 3$)$. Goodness of fit 
was assessed. The relative risk for unintentional injury-related infant death in rural versus urban counties was 1.7 (95\% CI: 0.9- 3.3) (Table 4).

\section{Discussion}

In this retrospective study of the West Virginia infant population between 2010 and 2014, the rurality was not associated with unintentional injury-related infant death, but it was associated with smoking during pregnancy. Our hypothesis that the relative risk of unintentional injury-related infant death would be significantly higher in rural counties compared with urban counties, holding other variables in the model constant, was not affirmed. Maternal smoking during pregnancy and rurality interaction was marginally significant. However, this interaction was deemed not statistically associated with unintentional injury-related infant death because of the prior alpha cutoff for variable inclusion (alpha $=0.05)$.

A non-significant association between unintentional injury-related infant death and rurality, and the interaction of smoking during pregnancy and rurality, holding other variables in the model constant, did not affirm findings from previous research. $[3,5,6,23,24]$ Risk of infants dying from an unintentional injury-related cause in rural counties relative to counterparts in urban counties was 1.7 (95\% CI: 0.9-3.3). Even though the interaction of smoking during pregnancy and rurality was marginally significant, it was eliminated from the model. The lack of association in the relationship in unintentional injury-related infant deaths between rural counties and urban counties might be partially explained by few cases of infant death and the population distribution in rural and urban counties in West Virginia. Approximately half of the population reside in rural areas, most of the counties classified as urban are not located in large metropolitan areas (Figure 1). There is no urbanized area or urban clusters with a population of quarter of a million or more in West Virginia.[25] Infant deaths associated with unintentional injury were few making the expected cell count less than 5 in some instances, as indicated in Table 1. 
Past research investigating the overall relationship between infant mortality and rurality found that poverty and very rural counties were associated with infant mortality, $[3,5,6,23,24]$ even though these studies, to our knowledge, focused their investigations on the U.S. as a whole or regionally rather than on a single state. Singh and Siahpush noted positive associations between rurality and all-cause mortality rates in the U.S. during the period 1969-2009,[7] whereas Spencer and colleagues found differences in age-adjusted mortality rates between rural and urban counties in the U.S.[5] Furthermore, Womack and colleagues noted that the infant mortality rate increased with rurality and Johansson found that smoking during pregnancy was associated with higher infant mortality, $[3,13]$ which is corroborated by this study. Infants of women not smoking or with unknown smoking status smoking during pregnancy had a decreased risk of unintentional injury-related death compared to infants of women who smoked during pregnancy $(\mathrm{RR}=0.3 ; 95 \% \mathrm{CI}: 0.2-0.8)$. These findings highlight the need for community evidence-based smoking cessation programs for pregnant women in both rural and urban counties given the high prevalence of maternal smoking during pregnancy in West Virginia. According to past research, up to $67 \%$ of women in West Virginia smoked during their final 3 months of pregnancy.[26]

Medicaid coverage was not associated with unintentional injury-related infant death. It is known that poverty is associated with excess risk of infant death, [5] and since Medicaid coverage is based on poverty level,[27,28] this finding was not expected even though such a relationship might be explained by substantial use of Medicaid insurance during pregnancy, but also racial/ethnic distribution and small sample size. Past studies document rural and small-town population to be approximately $78 \%$ White Non-Hispanic, whereas Hispanic and Black persons 
comprised approximately $18 \%$. Conversely, the urban population comprised $44 \%$ White NonHispanic persons and 45\% Hispanic and Black persons. [29,30]

In this study, over $97 \%$ of births were of race/ethnicity other than Non-Hispanic African American, and approximately 50\% of all births involved Medicaid insurance, and the U.S. census reported that approximately $51 \%$ of the West Virginia population lived in rural counties in 2010.[4] Therefore, population distribution, racial/ethnic distribution, extensive use of Medicaid insurance, and small numbers of unintentional injury-related infant deaths could be some of the factors influencing absence of an association between Medicaid insurance and unintentional injury-related infant death in this study. Usually, lack of insurance is one of the main barriers to healthcare access,[12] and the non-Hispanic Black population is usually associated with high infant mortality rates compared to non-Hispanic White infant mortality rates in the U.S.,[3] However, the Black population in West Virginia is negligible, and past studies have documented that Medicaid use during pregnancy protects against adverse perinatal outcomes. $[8,12]$

\section{Strengths and limitations}

To the authors' knowledge, this study is the only one using the proposed CDC external cause of death matrix to study unintentional injury-related infant deaths in West Virginia, as related to rurality. Findings should be interpreted with caution given the observed skew in the racial/ethnic population distribution. Additional study limitations are misclassification errors. Information errors, cause of death coding errors, [31] and the inherent complexity of forensic investigation may also contribute to the inadvertent misclassification of injury-related fatality cases regarding manner of injury death.[32] Such misclassifications could either push the relative risk towards or away from the null. In addition, the data used here were originally collected for 
administrative purposes and not epidemiologic research, which introduces the potential for some bias and unreliability.[33]

\section{Conclusion}

Rurality in West Virginia was not associated with the unintentional injury-related death rate among infants. Nevertheless, this rate was associated with maternal smoking during pregnancy. The results of this analysis underscore the importance of continued expansion of community-based unintentional injury-related infant reduction programming targeted towards pregnant women in both rural and urban counties who characterize themselves as smokers.

Future research is necessary to investigate these differences using multi-year data to increase the numbers of the observed outcome. 


\section{References}

1. Unites States National Research Council and Institute of Medicine. U.S. Health in International Perspective: Shorter Lives, Poorer Health. In: Woolf SH, Aron L, eds. U.S. Health in International Perspective: Shorter Lives, Poorer Health. Washington (DC) 2013.

2. Unites States National Research Council and Institute of Medicine. U.S. Health in International Perspective: Shorter Lives, Poorer Health. Vol 1812016.

3. Womack LS, Rossen LM, Hirai AH. Urban-Rural Infant Mortality Disparities by Race and Ethnicity and Cause of Death. American journal of preventive medicine. 2019.

4. The United States Census Bureau. West Virginia 2010 population and housing unit counts. Washington, DC: The United States Census Bureau;2012.

5. Spencer JC, Wheeler SB, Rotter JS, Holmes GM. Decomposing Mortality Disparities in Urban and Rural U.S. Counties. Health services research. 2018;53(6):4310-4331.

6. Mohamoud YA, Kirby RS, Ehrenthal DB. Poverty, urban-rural classification and term infant mortality: a population-based multilevel analysis. BMC pregnancy and childbirth. 2019;19(1):40.

7. Singh GK, Siahpush M. Widening rural-urban disparities in all-cause mortality and mortality from major causes of death in the USA, 1969-2009. Journal of urban health: bulletin of the New York Academy of Medicine. 2014;91(2):272-292.

8. Xaverius P, Alman C, Holtz L, Yarber L. Risk Factors Associated with Very Low Birth Weight in a Large Urban Area, Stratified by Adequacy of Prenatal Care. Maternal and child health journal. 2016;20(3):623-629. 
9. Devoe JE, Baez A, Angier H, Krois L, Edlund C, Carney PA. Insurance + access not equal to health care: typology of barriers to health care access for low-income families. Ann Fam Med. 2007;5(6):511-518.

10. DeVoe JE, Krois L, Stenger R. Do children in rural areas still have different access to health care? Results from a statewide survey of Oregon's food stamp population. The Journal of rural health : official journal of the American Rural Health Association and the National Rural Health Care Association. 2009;25(1):1-7.

11. Gage TB, Fang F, O'Neill E, Dirienzo G. Maternal education, birth weight, and infant mortality in the United States. Demography. 2013;50(2):615-635.

12. Johnelle Sparks P. One size does not fit all: an examination of low birthweight disparities among a diverse set of racial/ethnic groups. Maternal and child health journal. 2009;13(6):769-779.

13. Johansson AL, Dickman PW, Kramer MS, Cnattingius S. Maternal smoking and infant mortality: does quitting smoking reduce the risk of infant death? Epidemiology. 2009;20(4):590-597.

14. West Virginia Bureau for Public Health. West Virginia vital statistics, 2014. In: Resources WVDoHaH, ed. Charleston, WV: West Virginia Department of Health and Human Resources, Bureau for Public Health, Health Statistics Center; 2016:184.

15. The United States Department of Agriculture ERS. Urban influence codes. 2013; https://www.ers.usda.gov/data-products/urban-influence-codes.aspx. Accessed February $14,2020$. 
16. Annest J, Hedegaard H, Chen L, Warner M, Small E. Proposed Framework for Presenting Injury Data using ICD-10-CM External Cause of Injury Codes. National health statistics reports. 2014:1-32.

17. Stokes ME, Davis CS, Koch GG. Categorical data analysis using the SAS 3rd ed. Cary, NC: SAS Institute; 2012.

18. Agresti A. An introduction to categorical data analysis. 2nd ed. Hoboken, NJ: WileyInterscience; 2007.

19. Ballinger GA. Using Generalized Estimating Equations for Longitudinal Data Analysis. Organizational Research Methods. 2016;7(2):127-150.

20. UCLA Statistical Consulting Group. Introduction to SAS. 2020; https://stats.idre.ucla.edu/sas/faq/how-can-i-estimate-relative-risk-in-sas-using-procgenmod-for-common-outcomes-in-cohort-studies/. Accessed January 20, 2020.

21. Wacholder S. Binomial regression in GLIM: estimating risk ratios and risk differences. American journal of epidemiology. 1986;123(1):174-184.

22. SAS Institute. SAS/STAT software SAS Institute Inc; 2012.

23. Singh GK, Azuine RE, Siahpush M, Kogan MD. All-cause and cause-specific mortality among US youth: socioeconomic and rural-urban disparities and international patterns. Journal of urban health : bulletin of the New York Academy of Medicine. 2013;90(3):388-405.

24. Singh GK, Kogan MD, Slifkin RT. Widening Disparities In Infant Mortality And Life Expectancy Between Appalachia And The Rest Of The United States, 1990-2013. Health affairs. 2017;36(8):1423-1432. 
25. The United States Census Bureau. West Virginia: 2010 population and housing unit counts. The U.S. Census Bureau; 2012 2012. CPH-2-50.

26. Ahmadi-Montecalvo H, Haile ZT, Umer A, Chertok IR. Adolescent Pregnancy and Smoking in West Virginia: Pregnancy Risk Assessment Monitoring System (PRAMS) 2005-2010. Maternal and child health journal. 2016;20(12):2465-2473.

27. Clapp MA, James KE, Kaimal AJ, Sommers BD, Daw JR. Association of Medicaid Expansion With Coverage and Access to Care for Pregnant Women. Obstetrics and gynecology. 2019;134(5):1066-1074.

28. Tucker W, Zachary C. Medicaid Coverage for Pregnant Women: A Pathway to Healthy Outcomes for Moms and Children. N C Med J. 2020;81(1):51-54.

29. The United States Department of Agriculture ERS. Rural America at a glance. Washington, DC: United States Department of Agriculture; 2018.

30. The Housing Assistance Council. Race and ethnicity in rural America. Washington, DC: The Housing Assistance Council; 2012.

31. McGivern L, Shulman L, Carney JK, Shapiro S, Bundock E. Death Certification Errors and the Effect on Mortality Statistics. Public health reports. 2017;132(6):669-675.

32. Byard RW, Shipstone RA, Young J. Continuing major inconsistencies in the classification of unexpected infant deaths. J Forensic Leg Med. 2019;64:20-22.

33. Northam S, Knapp TR. The reliability and validity of birth certificates. Journal of obstetric, gynecologic, and neonatal nursing : JOGNN. 2006;35(1):3-12. 
Tables and Figures 
Table 1: Characteristics of unintentional injury-related infant deaths in West Virginia, 2010-2014

\begin{tabular}{|c|c|c|c|}
\hline Variable & Category & Death (\%) ${ }^{+}$ & P-Value \\
\hline \multirow[t]{2}{*}{ Urbanicity } & Rural & $15(0.04)$ & \\
\hline & Urban & $14(0.02)$ & $0.1279 *$ \\
\hline \multirow[t]{2}{*}{ Smoking During Pregnancy } & No/Unknown & $14(0.02)$ & \\
\hline & Yes & $15(0.06)$ & $0.0022 *$ \\
\hline \multirow[t]{2}{*}{ African American Non-Hispanic } & Yes & $3(0.08)$ & \\
\hline & No & $26(0.03)$ & $0.0793 * *$ \\
\hline \multirow[t]{2}{*}{ Medicaid Use During Pregnancy } & Yes & $10(0.03)$ & \\
\hline & No or Unknown & $19(0.03)$ & $0.6833^{*}$ \\
\hline \multirow[t]{2}{*}{ Maternal Education } & HS or less & $6(0.04)$ & \\
\hline & More than HS & $23(0.03)$ & $0.4516 * *$ \\
\hline \multirow[t]{2}{*}{ History of Diabetes } & Yes & $1(0.02)$ & \\
\hline & No & $28(0.03)$ & $1.0000 * *$ \\
\hline \multirow[t]{2}{*}{ History of Hypertension } & Yes & $2(0.03)$ & \\
\hline & No & $27(0.03)$ & $1.0000 * *$ \\
\hline \multirow[t]{3}{*}{ Maternal Age (years) } & $\geq 20$ & $4(0.02)$ & \\
\hline & $21-39$ & $19(0.03)$ & \\
\hline & $40+$ & $5(0.02)$ & $0.6564 *$ \\
\hline \multirow[t]{2}{*}{ Infant Sex } & Female & $15(0.03)$ & \\
\hline & Male & $14(0.03)$ & $0.7761^{*}$ \\
\hline \multirow[t]{2}{*}{ Birth Weight (grams) } & $\leq 2499$ & $5(0.02)$ & \\
\hline & $2500+$ & $24(0.03)$ & $0.1838 * *$ \\
\hline
\end{tabular}


Table 2: Parameter estimates for unintentional injury-related infant deaths in West Virginia, 2010-2014

\begin{tabular}{|c|c|c|c|c|c|c|c|}
\hline \multirow{2}{*}{ Parameter } & \multirow{2}{*}{ Category } & \multicolumn{2}{|c|}{ Logistic model** } & \multicolumn{2}{|c|}{$\begin{array}{l}\text { GLMM 1*: non- } \\
\text { parsimonious }\end{array}$} & \multicolumn{2}{|c|}{$\begin{array}{l}\text { GLMM 2*: } \\
\text { Parsimonious }\end{array}$} \\
\hline & & Estimate & P-Value & Estimate & P-Value & Estimate & p-value \\
\hline Intercept & & -7.6 & $<.0001$ & -8.3 & $<.0001$ & -7.7983 & $<.0001$ \\
\hline Rurality & $\begin{array}{l}\text { Rural } \\
\text { No and }\end{array}$ & -0.3 & 0.2072 & 1.3 & 0.0296 & 0.5546 & 0.0905 \\
\hline Smoking During Pregnancy & $\begin{array}{l}\text { Unknown } \\
\text { Non-Hispanic }\end{array}$ & -0.5 & 0.0115 & -0.2 & 0.7758 & -1.0619 & 0.0086 \\
\hline $\begin{array}{l}\text { Maternal Race/Ethnicity } \\
\text { Rurality-Smoking During }\end{array}$ & $\begin{array}{l}\text { Black } \\
\text { Rural and No }\end{array}$ & 0.6 & 0.0355 & - & - & - & - \\
\hline Pregnancy Interaction & \& Unknown & 0.4 & 0.0475 & -1.7 & 0.0704 & - & - \\
\hline
\end{tabular}

Table 3: Risks of unintentional injury-related infant deaths in selected characteristics, West Virginia 2010-2014

\begin{tabular}{|c|c|c|}
\hline Variable Comparisons & Relative Risk & $\begin{array}{c}\text { 95\% Confidence Interval of the } \\
\text { Relative Risk }\end{array}$ \\
\hline Rural Counties vs. Urban Counties & 1.7 & $(0.9-3.3)$ \\
\hline No \&Unknown vs. Smoking During Pregnancy & 0.3 & $(0.2-0.8)$ \\
\hline
\end{tabular}


Figure 1: Rurality in West Virginia, 2010-2014

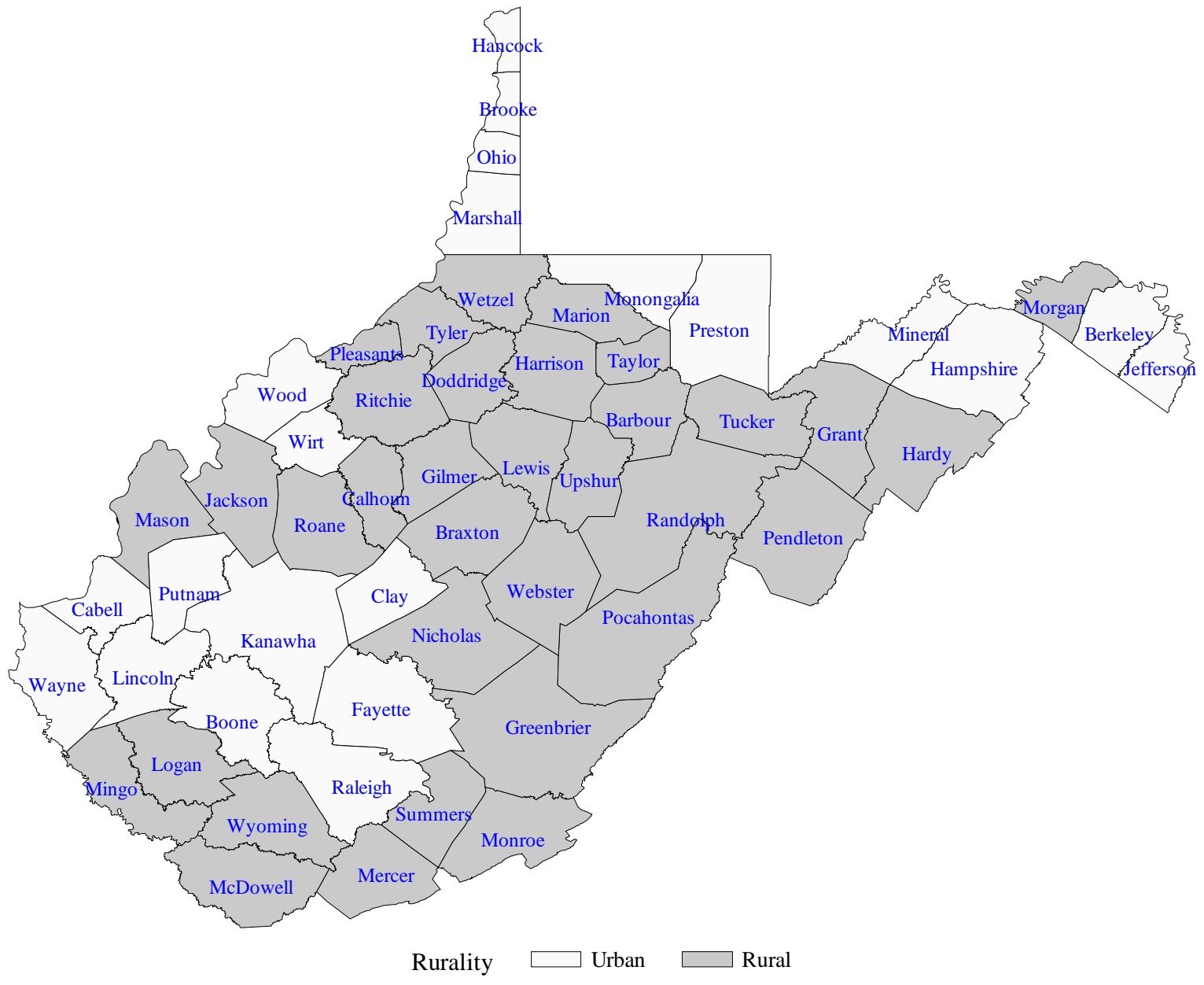




\section{Chapter 4}

Unintentional injury-related infant mortality in West Virginia and the United States, 2010-2014 


\section{Abstract \\ Objective}

To investigate and describe differences in the intentional-injury related infant mortality rates between West Virginia and the United States, stratified by race/ethnicity.

\section{Methods}

De-identified and linked birth/death vital records for 2010-2014 cohorts were provided by the West Virginia Bureau for Public Health, Charleston, WV, and the U.S. linked birth/death vital records for 2010-2014 cohorts was accessed from the Centers for Disease Control and Prevention (CDC) website. The unintentional injury-related infant mortality rate was the dependent. The non model-based formula for calculating injury-related mortality rate that follows a simple Poisson distribution was used to calculate infant mortality rates and their $95 \%$ confidence intervals, stratified by race/ethnicity.

\section{Results}

The unintentional injury-related infant mortality rate stratified by race/ethnicity was 57.5 (95\% CI, 54.8-60.3) deaths per 100,000 live births among the Non-Hispanic Black population at the national level, and 83.2 (95\% CI, 26.8-258.0) deaths per 100,000 live births among the NonHispanic Black population in West Virginia during the 2010-2014 observation period.

\section{Conclusion}

Stratified by race/ethnicity, the observed unintentional injury-related infant mortality rates in West Virginia were higher than corresponding national rates, but these differences were not statistically significant. 


\section{Introduction}

Unlike those in other developed nations, the 2010 infant mortality rate in the United States (U.S.) did not reflect any noticeable improvement.[1] Respective national infant mortality rates (IMRs) were 6.14 deaths per 1,000 live births in 2010, 6.05 in 2011, and 5.82 in 2014.[2-4] By comparison, the IMRs in Finland, Germany and United Kingdom in 2010 were 2.3, 3.4 and 4.2 deaths per 1,000 live births, respectively.[1]

Within the U.S., the IMR and other key health indicators vary greatly by region. In particular, the health disparities gap is widening in Appalachia relative to other parts of the country. Local IMRs in parts of Appalachia are among the highest in the country; for example, in 2013 the overall IMR was 9.6 per 1,000 live births in Mississippi, 8.6 per 1,000 live births in Alabama, and 6.7 per 1,000 live births in Pennsylvania.[5] From 1990 to 2013, life expectancy at birth in Appalachia decreased by 2.4 years on average, and the IMR for the Black population rose approximately $16 \%$ relative to that for the White population.[6]

The only state fully immersed in Appalachia, West Virginia is among the states with the highest IMRs in the U.S.[5] According to the West Virginia Bureau for Public Health, 7.3 deaths per 1,000 live births were documented in 2010 and 7.1 deaths per 1,000 live births in 2014.[7] Together with life expectancy at birth, the IMR is a key indicator of population health, and West Virginia exhibits numerous characteristics associated with high infant fatalities.[8] They include rurality, inaccessible topography, high levels of poverty, lack of education, health insurance, and access to healthcare. [6,9-13]

In addition to the IMR, the unintentional injury-related infant mortality rate (UIIMR) is a valuable indicator of overall population health. Unintentional injury-related causes are associated with most childhood deaths in the U.S, and the rates of such deaths among infants increased from 
23.1 to 27.7 deaths per 100,000 births.[14] Means or mechanisms of unintentional injury-related infant mortality include vehicles, firearms, poison, drowning, and choking objects.[15,16]

Understanding infant mortality is the first step in understanding community socioeconomic and health conditions of a community.[17] It follows, then, that a valuable way of evaluating areas for infant mortality reduction is to focus attention on totally or partially preventable causes of infant death. This study compares IMRs and UIIMRs in West Virginia with national rates from 2010 through 2014, with a specific focus on infant mortality by such manner or intents that can be completely or partially preventable.[18] The main study objective is to investigate and describe the UIIMRs in West Virginia, in comparison to national UIIMRs, and to stratify comparisons by race/ethnicity. The hypothesis is that UIIMR in West Virginia is significantly higher than the national rate. Findings will inform public health stakeholders on socio-economic issues and character of West Virginia infant mortality. High infant mortality rate is associated with poverty, lack of nutritious food, poor healthcare access and low education.[19] Therefore, understanding UIIMR will support the design of targeted, effective, and communitybased preventive measures. Additionally, findings will act as a measure on the effectiveness of current infant mortality intervention strategies.

\section{Materials and methods}

Data sources. Data used in this study were sourced from two sites: 1) de-identified and linked birth/death vital records for 2010-2014 cohorts obtained from the West Virginia Bureau for Public Health, Charleston, WV, and 2) the U.S. linked birth/death vital records for 2010-2014 cohorts accessed from the Centers for Disease Control and Prevention (CDC) website.[20]

Dependent variable. The unintentional injury-related infant mortality rate (UIIMR) was the dependent or outcome variable. Injury-related infant deaths were categorized into two groups based on manner: accidents/unintentional injury-related infant deaths and intentional 
injury-related infant deaths. International Classification of Diseases 10th revision (ICD-10) codes for unintentional injury-related infant fatalities are V01-X59 and Y85-Y86. Infants with unknown gestational weeks or birth weight, women with unknown age, and infant death associated with causes other than accidental or intentional injury were excluded from the study.

Independent variables. Independent variables included both maternal and infant characteristics. Maternal characteristics comprised age (20 years or less, 21-39 years, 40 years or more), smoking status during pregnancy (smoked, did not smoke, or unknown), race/ethnicity (Non-Hispanic Black, Other), and education (high school or less, more than high school). Infant characteristics comprised sex (male, female) and birth weight (2500 grams or less, more than 2500 grams).

Statistical analysis. Descriptive statistics were calculated and presented in figures and tables. Statistics were the mean, standard deviation, injury-related infant mortality rate and associated 95\% confidence intervals (CI). Calculation of the UIIMR was derived from a nonmodal based formula for calculating injury-related mortality rate that follows a simple Poisson distribution.[21] The formula used to calculate UIIMR and UIIMR 95\% CL is presented below:

$$
\begin{gathered}
U I I M R=\left(\frac{\text { unweighted count dying from related manner of injury }}{\text { live births exposed to related manner of injury }}\right) \times 100,000 \\
95 \% C L=\exp \left\{\log (\text { UIIMR })-1 \cdot 96 \times \sqrt{\frac{1}{\text { died }}}\right\}, \exp \left\{\log (\text { UIIMR })+1 \cdot 96 \times \sqrt{\frac{1}{\text { died }}}\right\}
\end{gathered}
$$

Legend

UIIMR $=$ unintentional injury-related infant mortality rate

Died $=$ unweighted count dying from related manner of injury

Exp $=$ exponential 
$95 \% \mathrm{CL}=95$ percent confidence limit

After the IIMR was calculated, West Virginia rates were compared to national U.S. rates. SAS/STAT software (version 9.4, SAS Institute, Cary, NC) was used for data management and analysis.[22]

\section{Results}

There were approximately 20 million live births and 118,000 infant deaths reported in the U.S. during the 2010-2014 observation period. Annual mean live births and annual mean infant deaths were 3,965,215 (standard deviation $=27,703)$ and 23,535 (standard deviation $=479)$, respectively. In West Virginia, a total of 103,424 live births and 746 infant deaths were reported during the observation period. Annual mean live births in West Virginia were 20,685 (standard deviation $=150)$ and annualized mean infant deaths were $149($ standard deviation $=8)$. Approximately $93 \%$ and 3\% of live births were White Non-Hispanic and Non-Hispanic Black, respectively.

After removing participants that did not meet inclusion criteria, there were 739 and 117,6774 infant deaths in West Virginia and the U.S., respectively. Average IMRs in the U.S. and West Virginia during the observation period were 5.9 and 7.2 per 1000 live births, respectively (Table 1).

The U.S. UIIMR was 28.4 (95\% CI, 27.7-29.2) deaths per 100,000 live births, whereas in West Virginia it was 28.0 (95\% CI, 19.5-40.4) in 2010-2014 period. Moreover, the UIIMR stratified by race/ethnicity was 57.5 (95\% CI, 54.8-60.3) deaths per 100,000 live births among the Non-Hispanic Black population at the national level, and 83.2 (95\% CI, 26.8-258.0) deaths per 100,000 live births among the Non-Hispanic Black population in West Virginia during 20102014 period (Tables 1 and Figure 1-6). 


\section{Discussion}

The main aim of this study was to investigate accidental/unintentional injury-related infant mortality rate in West Virginia in comparison with the national accidental/unintentional injury-related infant mortality rate, stratified by race/ethnicity. Unintentional injuries were the leading cause of injury-related infant deaths in the U.S. and West Virginia between 2010 and 2014. The UIIMRs in West Virginia and the U.S. in the five-year study period were similar. Recorded UIIMRs were 28.0 (95\% CI, 19.5-40.4) and 28.4 (95\% CI, 27.7-29.2) deaths per 100,000 live births in West Virginia and the U.S., respectively. This is an unexpected finding because age-adjusted unintentional injury deaths in rural areas and among the overall U.S. population have been increasing.[10] Other studies have associated UIIMRs with low socioeconomic status, poor access to health care, and lack of education. Yet the West Virginia rate approximated the national rate. In this study, half of West Virginia's female population giving birth between 2010-2015 had a high school diploma/GED or less or used Medicaid during pregnancy and resided in rural counties. Use of Medicaid insurance could imply a reduction in financial barriers to healthcare access,[13] hence overshadowing the impact of the high prevalence of low educational levels in West Virginia. Education was not found to be significantly associated with unintentional injury-related mortality, but it is known to be one of the factors associated with overall infant mortality. Some studies corroborate the deduction that Medicaid use provides protective health effects.[6] Approximately 50\% of West Virginian women utilized Medicaid insurance during pregnancy, and studies show that West Virginia experienced a sharp decline in uninsured women of childbearing age following expansion of the Affordable Health Care Act (ACA) in 2010.[23] Such expansion made healthcare accessible to most women, hence lowering poor perinatal outcomes. 
Another contributing factor to the observed similarities between West Virginian and national rates could be the racial/ethnic character of the population under study. Approximately $90 \%$ of annual live births were born to White Non-Hispanic women in West Virginia. Generally, the IMR in the White Non-Hispanic population tends to be the same or lower than the total population rate, $[4,5,24]$ and that was the case in this study. Research findings did not support the hypothesis. The unintentional injury-related infant mortality rate gap between White NonHispanic infants and Non-Hispanic Black infants was greater at the state level than at the national level, but the difference was not statistically significant.

Racial/ethnic disparities in unintentional injury-related infant deaths exist equally at state and national levels. The UIIMR for Non-Hispanic Black infants at the state level was 83.2 deaths per 1000 live births (95\% CI, 26.8-258.0) and 57.5 deaths per 1000 live births (95\% CI, 54.860.3) nationwide, whereas the rate for other races/ethnicities at the state level was 26.1 deaths per 1000 live births (95\% CI, 17.8-38.4) and 23.4 deaths per 1000 live births (95\% CI, 22.724.1) nationwide. A racial/ethnic infant mortality disparity is well documented in the literature $[5,6,9]$, and seems inherent in unintentional injury-related infant mortality. Less than $4 \%$ of the infant population in West Virginia was Non-Hispanic Black. Although the confidence interval calculation for the mortality rates from this population is unreliable, observed differences between UIIMRs for Non-Hispanic Black infants and infants of other races/ethnicities were large. Conversely, over $90 \%$ of the West Virginia infant population were non-Hispanic White, and it is well documented this population usually has more favorable outcomes than other racial/ethnic populations.[12] The combination of skew in the racial/ethnic population distribution and the protective effect of Medicaid could account for the similarity between the West Virginian and national UIIMRs. 


\section{Strengths and limitations}

This analysis is the only one that uses the CDC external cause of death matrix to study unintentional injury-related infant deaths in West Virginia. Results from this analysis must be interpreted with caution, however, due to the skew in racial/ethnic distribution in the study population.[25] Other known limitations include potential errors in coding[26] and complex forensic investigations.[27] Misclassification could either push the relative risk towards or away from the null. Information bias may also impact these data because they were originally collected for administrative purposes not for epidemiologic research.[28]

\section{Conclusion}

Unintentional injury-related infant mortality rates, stratified by race/ethnicity, in West Virginia are higher than national rates. However, the differences are not statistically significant. The number of Non-Hispanic Black infant deaths associated with unintentional injury-related causes is more than twice those for other racial/ethnic groups, be it in West Virginia or nationally.

State- and community-based intervention approaches need to be re-engineered to meet the needs of the minority population of West Virginia. Life course theory has been suggested by some scholars as a new approach for reducing racial/ethnic disparities in infant mortality. Therefore, future research on unintentional injury-related infant mortally in West Virginia should evaluate the theory in this context. 


\section{References}

1. MacDorman MF, Matthews TJ, Mohangoo AD, Zeitlin J. International comparisons of infant mortality and related factors: United States and Europe, 2010. National vital statistics reports : from the Centers for Disease Control and Prevention, National Center for Health Statistics, National Vital Statistics System. 2014;63(5):1-6.

2. Kochanek KD, Murphy SL, Xu J, Tejada-Vera B. Deaths: Final Data for 2014. National vital statistics reports : from the Centers for Disease Control and Prevention, National Center for Health Statistics, National Vital Statistics System. 2016;65(4):1-122.

3. MacDorman MF, Hoyert DL, Mathews TJ. Recent declines in infant mortality in the United States, 2005-2011. NCHS data brief. 2013(120):1-8.

4. Mathews TJ, MacDorman MF. Infant Mortality Statistics from the 2010 Period Linked Birth/Infant Death Data Set. National vital statistics reports : from the Centers for Disease Control and Prevention, National Center for Health Statistics, National Vital Statistics System. 2013;62(8):1-27.

5. Mathews TJ, MacDorman MF, Thoma ME. Infant mortality statistics from the 2013 period linked birth/infant death data set. National vital statistics reports : from the Centers for Disease Control and Prevention, National Center for Health Statistics, National Vital Statistics System. 2015;64(9):1-30.

6. Singh GK, Yu SM. Infant Mortality in the United States, 1915-2017: Large Social Inequalities have Persisted for Over a Century. Int J MCH AIDS. 2019;8(1):19-31. 
7. West Virginia Bureau for Public Health. West Virginia vital statistics, 2014. In:

Resources WVDoHaH, ed. Charleston, WV: West Virginia Department of Health and Human Resources, Bureau for Public Health, Health Statistics Center; 2016:184.

8. Ely DM, Driscoll AK, Mathews TJ. Infant mortality rates in rural and urban areas in the United States, 2014. Center for Disease Control and Prevention;2017.

9. Mathews TJ, Driscoll AK. Trends in Infant Mortality in the United States, 2005-2014. NCHS data brief. 2017(279):1-8.

10. Olaisen RH, Rossen LM, Warner M, Anderson RN. Unintentional Injury Death Rates in Rural and Urban Areas: United States, 1999-2017. NCHS data brief. 2019(343):1-8.

11. Ely DM, Hoyert DL. Differences Between Rural and Urban Areas in Mortality Rates for the Leading Causes of Infant Death: United States, 2013-2015. NCHS data brief. 2018(300):1-8.

12. Rossen LM, Schoendorf KC. Trends in racial and ethnic disparities in infant mortality rates in the United States, 1989-2006. American journal of public health. 2014;104(8):1549-1556.

13. Kronick R, Bindman AB. Protecting finances and improving access to care with Medicaid. N Engl J Med. 2013;368(18):1744-1745.

14. Centers for Disease Control and Prevention. Vital signs: Unintentional injury deaths among persons aged 0-19 years - United States, 2000-2009. MMWR Morbidity and mortality weekly report. 2012;61:270-276.

15. Theurer WM, Bhavsar AK. Prevention of unintentional childhood injury. American family physician. 2013;87(7):502-509. 
16. Rothman L, Clemens T, Macarthur C. Prevention of unintentional childhood injury: A review of study designs in the published literature 2013-2016. Prev Med Rep. 2019;15:100918.

17. Kim D, Saada A. The social determinants of infant mortality and birth outcomes in Western developed nations: a cross-country systematic review. International journal of environmental research and public health. 2013;10(6):2296-2335.

18. Schnitzer PG. Prevention of unintentional childhood injuries. American family physician. 2006;74(11):1864-1869.

19. Fiscella K, Williams DR. Health disparities based on socioeconomic inequities: implications for urban health care. Acad Med. 2004;79(12):1139-1147.

20. Period linked birth-infant death data files 2010-2014. Centers for Disease Control and Prevention; 2018. https://www.cdc.gov/nchs/data_access/vitalstatsonline.htm\#Period_Linked. Accessed July 24, 2018.

21. Kegler SR. Applying the compound Poisson process model to the reporting of injuryrelated mortality rates. Epidemiol Perspect Innov. 2007;4:1.

22. SAS Institute. SAS/STAT software SAS Institute Inc; 2012.

23. A. S, C. RD. Medicaid Expansion Fills Gaps in Maternal Health Coverage Leading to Healthier Mothers and Babies. Washington DC: Georgetown University Center for Children and Families, McCourt School of Public Policy; 2019.

24. Mathews TJ, MacDorman MF. Infant mortality statistics from the 2009 period linked birth/infant death data set. National vital statistics reports : from the Centers for Disease 
Control and Prevention, National Center for Health Statistics, National Vital Statistics System. 2013;61(8):1-27.

25. The United States Cancer Statistics. National Center for Health Statistics staff manual on confidentiality. 2004; 27. Available at: https://www.cdc.gov/cancer/uscs/technical_notes/stat_methods/suppression.htm. Accessed December 18, 2018.

26. McGivern L, Shulman L, Carney JK, Shapiro S, Bundock E. Death Certification Errors and the Effect on Mortality Statistics. Public health reports. 2017;132(6):669-675.

27. Byard RW, Shipstone RA, Young J. Continuing major inconsistencies in the classification of unexpected infant deaths. J Forensic Leg Med. 2019;64:20-22.

28. Northam S, Knapp TR. The reliability and validity of birth certificates. Journal of obstetric, gynecologic, and neonatal nursing : JOGNN. 2006;35(1):3-12. 
Tables and Figures 
Table 1: Infant mortality in West Virginia and the United States, 2010-2014

\begin{tabular}{lllll}
\hline \multirow{2}{*}{ Category } & \multicolumn{2}{l}{ West Virginia } & \multicolumn{2}{l}{ United States } \\
\cline { 2 - 5 } & $\begin{array}{l}\text { Infant } \\
\text { Deaths }\end{array}$ & IMR* & $\begin{array}{l}\text { Infant } \\
\text { Deaths }\end{array}$ & IMR* \\
\hline Race/Ethnicity & 29 & 8.0 & 32601 & 11.3 \\
$\quad \begin{array}{l}\text { Non-Hispanic Black } \\
\text { Other }\end{array}$ & 709 & 7.1 & 85073 & 5.1 \\
Year & & & & \\
2010 & 145 & 7.1 & 24273 & 6.1 \\
2011 & 146 & 7.1 & 23702 & 6.0 \\
2012 & 153 & 7.4 & 23425 & 5.9 \\
2013 & 155 & 7.5 & 23224 & 5.9 \\
2014 & 140 & 6.8 & 23050 & 5.8 \\
All Years & 739 & 7.2 & 117674 & 5.9 \\
\hline * IMR = Infant mortality rate. Unweighted infant deaths per 1,000 live births. \\
\hline
\end{tabular}

Table 2: Unintentional injury-related infant mortality in West Virginia and the United States, 2010-2014

\begin{tabular}{|c|c|c|c|c|c|}
\hline \multirow[b]{2}{*}{ Category } & \multirow[b]{2}{*}{ Category } & \multicolumn{2}{|c|}{ West Virginia } & \multicolumn{2}{|c|}{ United States } \\
\hline & & UIIMR* & $95 \% \mathrm{CI}^{++}$ & UIIMR* & $95 \% \mathrm{CI}^{++}$ \\
\hline Manner of & Intentional & 20.3 & $(13.2-31.1)$ & 8.8 & $(9.3-9.7)$ \\
\hline Deaun & Unintentional & 28.0 & $(19.5-40.4)$ & 28.4 & $(27.7-29.2)$ \\
\hline Intentional & Non-Hispanic & 83.2 & $(26.8-258.0)$ & 17.2 & $(15.8-18.8)$ \\
\hline Manner of & Black & & & & \\
\hline Death & $\begin{array}{l}\text { Other } \\
\text { Races/Ethnicities }\end{array}$ & 17.1 & $(10.6-27.5)$ & 7.9 & $(7.5-9.3)$ \\
\hline Unintentional & Non-Hispanic & 83.2 & $(26.8-258.0)$ & 57.5 & $(54.8-60.3)$ \\
\hline Manner of & Black & & & & \\
\hline Death & $\begin{array}{l}\text { Other } \\
\text { Races/Ethnicities }\end{array}$ & 26.1 & $(17.8-38.4)$ & 23.4 & $(22.7-24.1)$ \\
\hline
\end{tabular}


Figure 1: Related manner of injury-related infant deaths in West Virginia, 2010-2014

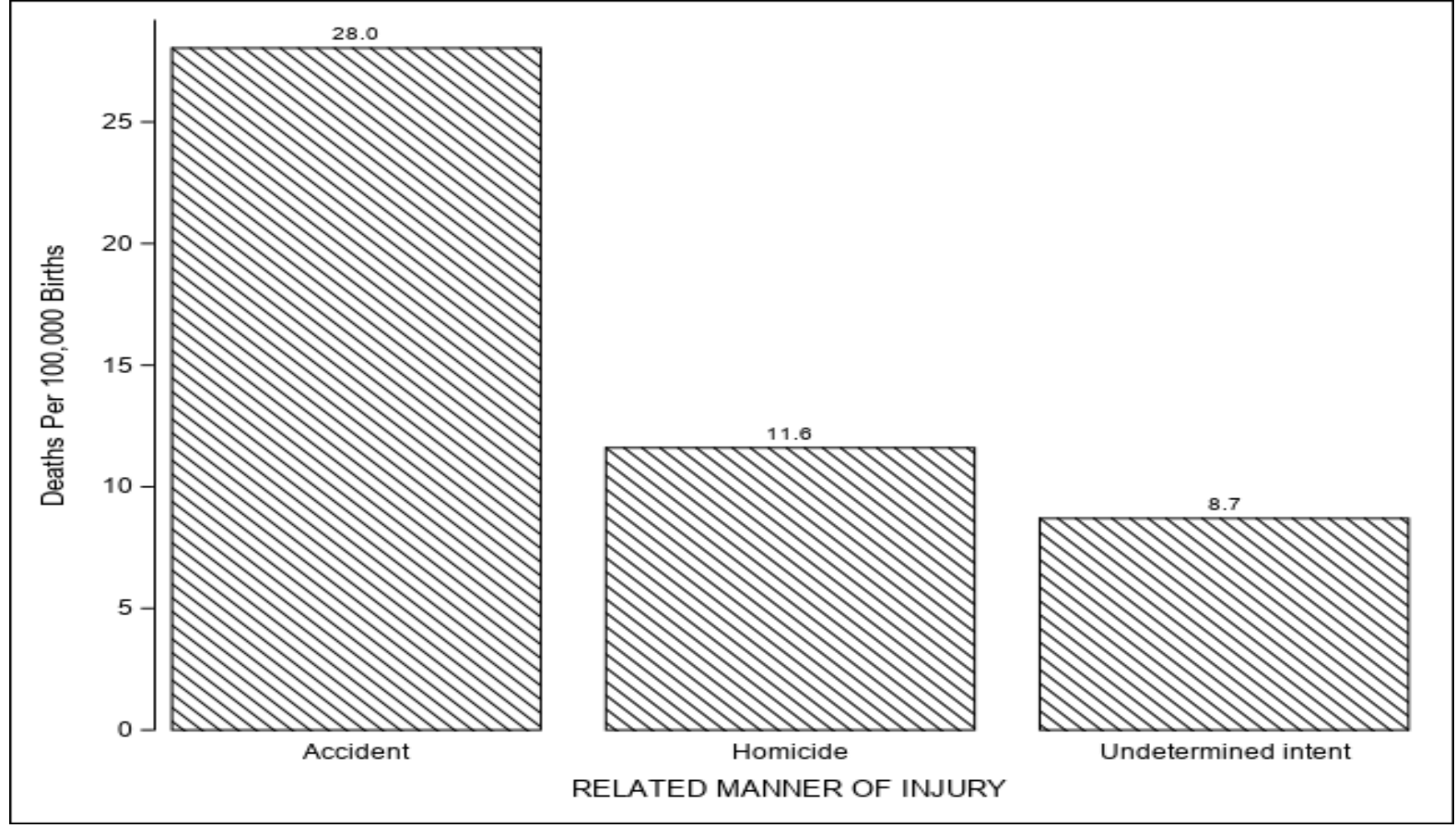

Figure 2: Related manner of injury-related infant deaths in West Virginia, 2010-2014

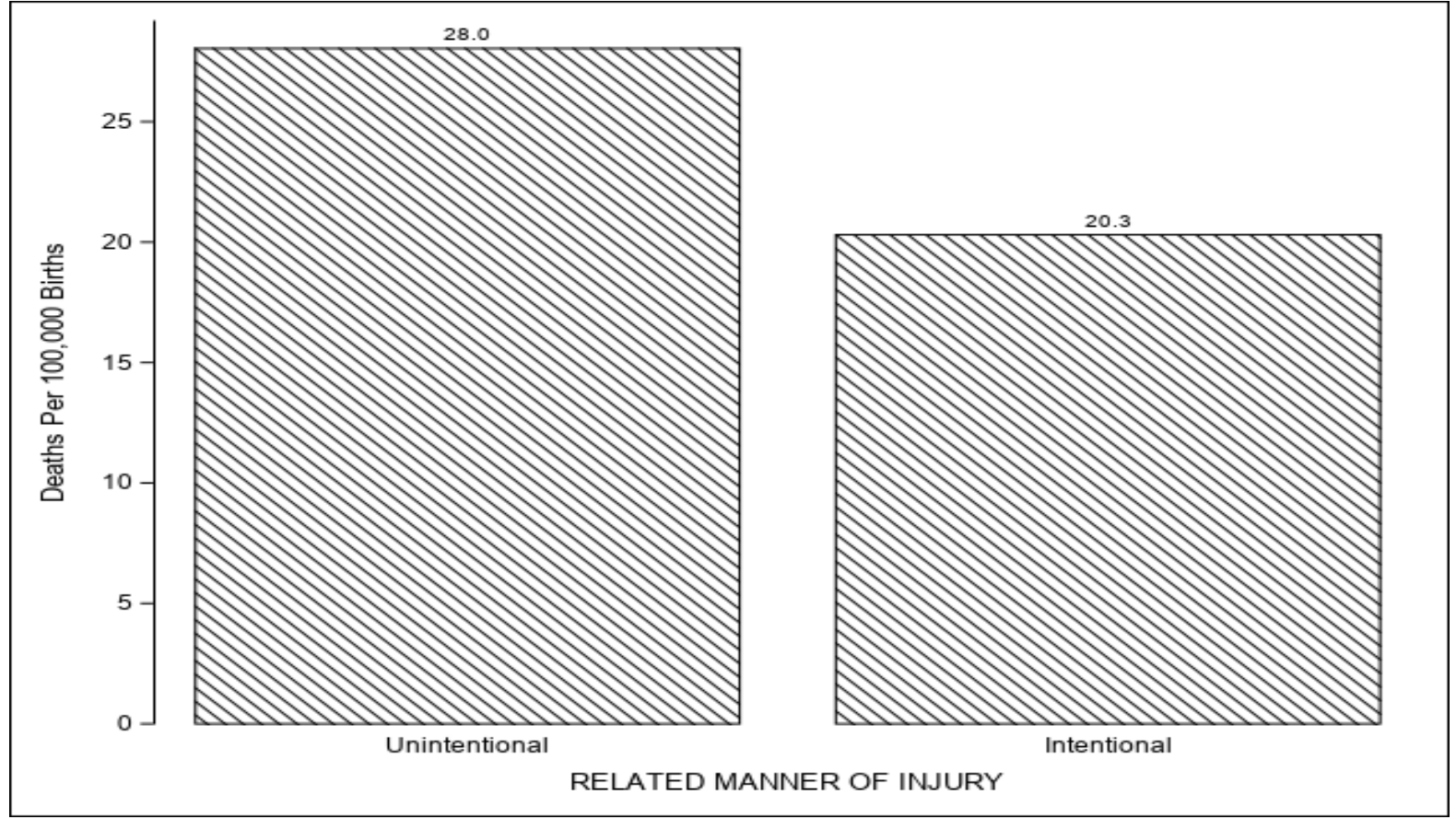


Figure 3: Related manner of injury-related infant deaths in West Virginia, 2010-2014

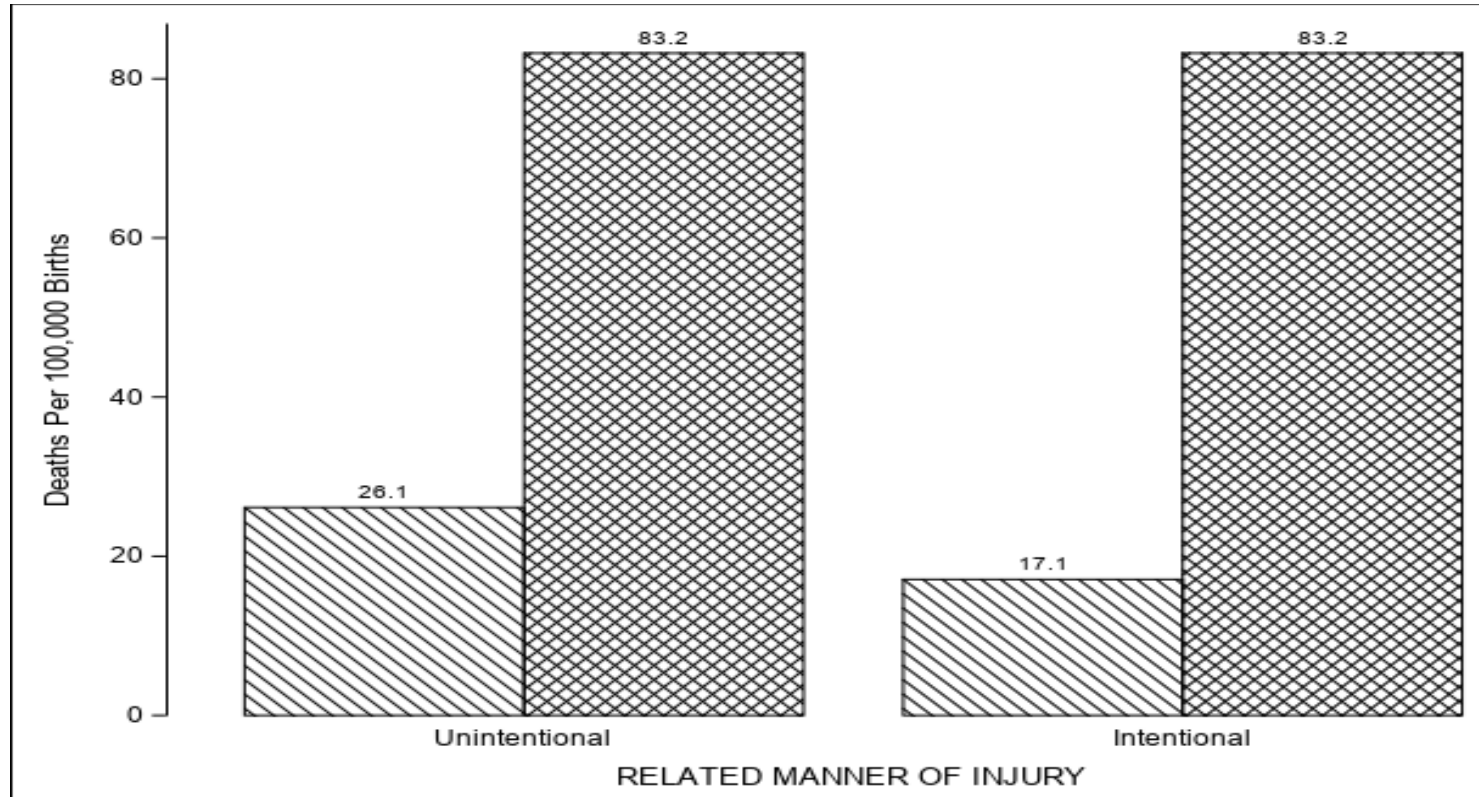

RACE/ETHNICITY $D V$ Other 2 African-American Non-Hispanic

Figure 4: Related manner of injury-related infant deaths in the United States, 2010-2014

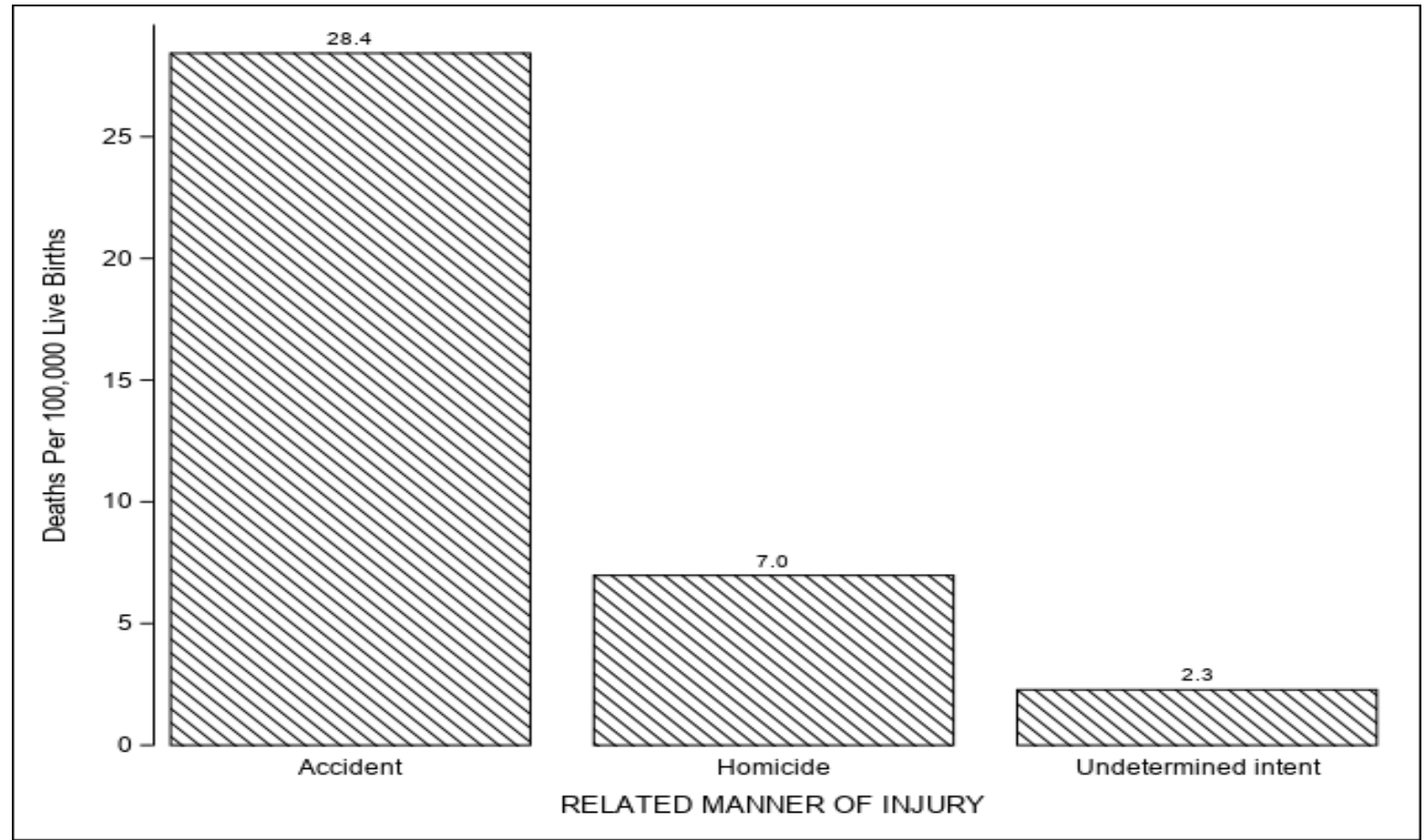


Figure 5: Related manner of injury-related infant deaths by intent in the United States, 20102014

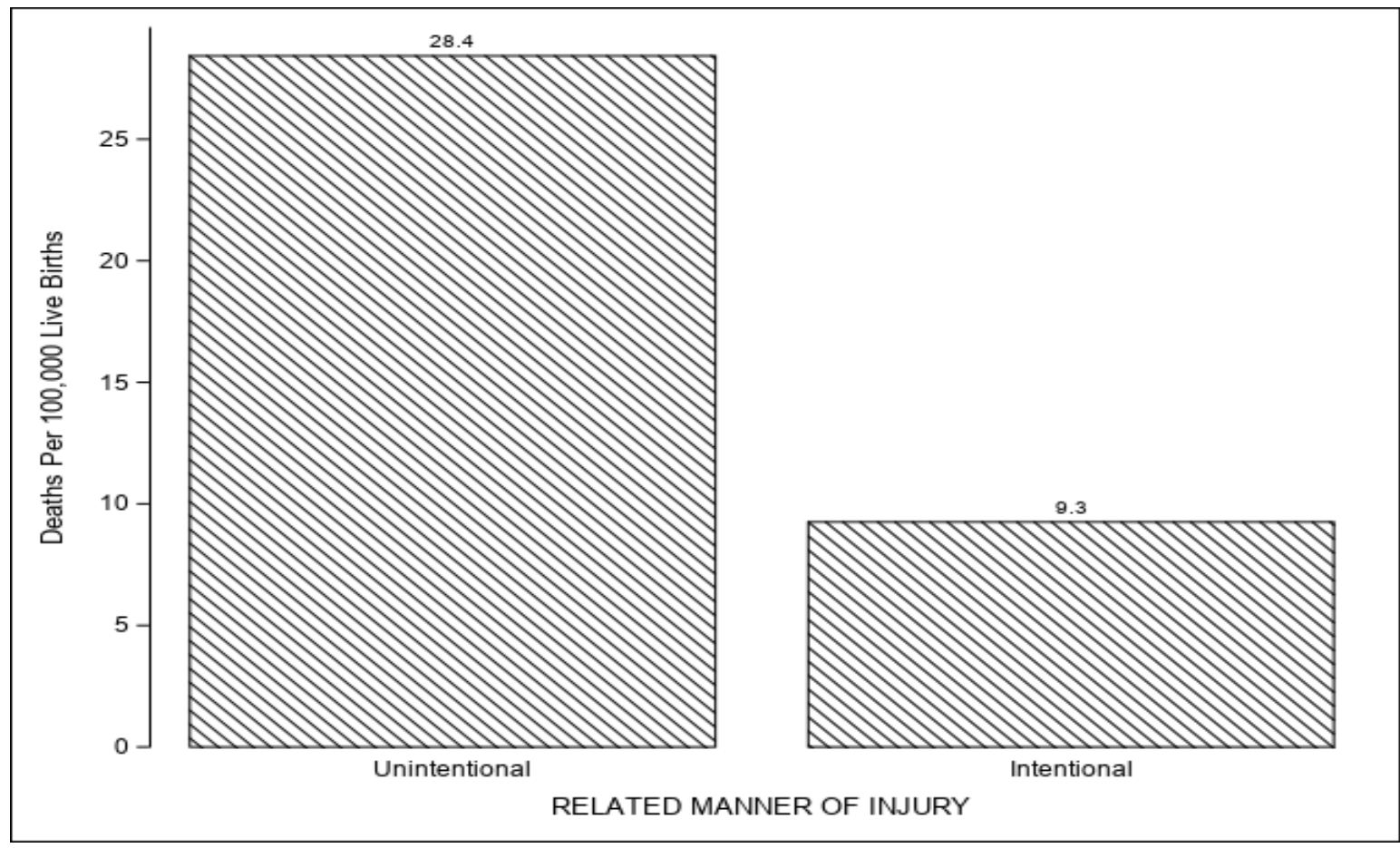

Figure 6: Related manner of injury-related infant deaths in the United States, stratified by race/ethnicity, 2010-2014

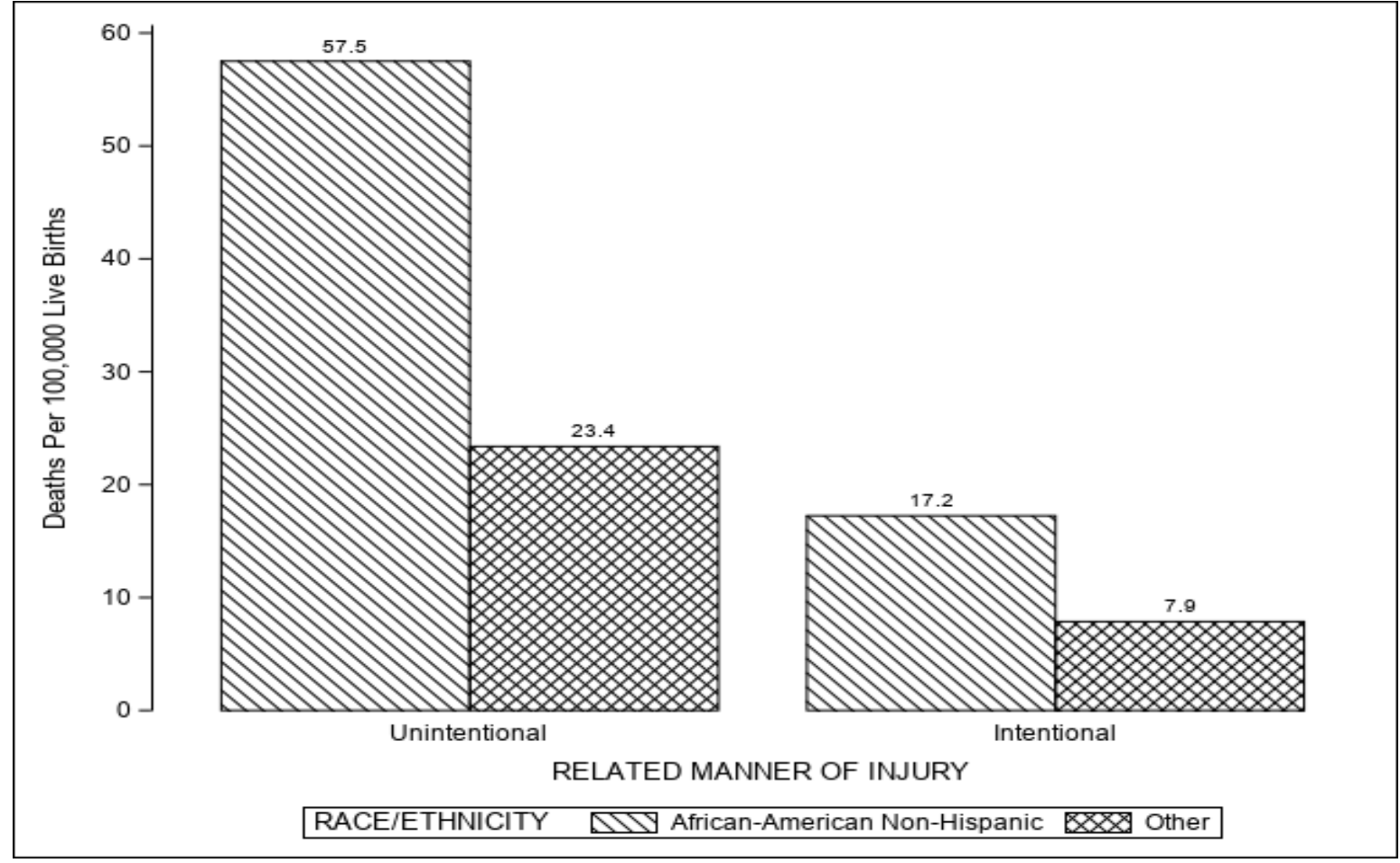




\section{Chapter 5}

Overall Discussions and Conclusion 


\section{Summary}

Although the infant mortality rate in the United States has decreased over the past decade, the rate of decrease is slow compared to other develop nations[1] The low infant mortality rate (IMR) is correlated with higher standards of living, and some scholars argue that the best way to decrease the IMR is to focus on improving distal factors in the community while others associate a declining IMR with improvement in proximal factors.[2,3] I argue, in part, that understanding maternal and infant characteristics associated with causes of infant death that are partially or completely preventable, and deploying the urban influence codes is indispensable to evaluating this question. Even though numerous studies have investigated characteristics associated with infant death,[4-12] a gap in the literature exists because none of these studies investigated injury-related infant death in West Virginia, a state where a homogenous medicallyunderserved Appalachian population lives within an equal balance of rural and urban areas. Furthermore, to the authors' knowledge, this study is the only one using the proposed CDC external cause of death matrix to study unintentional injury-related infant deaths in West Virginia, as related to rurality using 2010-2014 vital health data. Building on these contexts, this study investigated injury-related infant mortality and unintentional injury-related infant mortality (UIIM) in West Virginia with three specific hypothesizes: 1) injury-related infant death is associated with maternal and infant characteristics, adjusted for other factors in the model (Study 1), 2) the relative risk of unintentional injury-related infant death is significantly higher in rural counties than in urban counties, holding other variables in the model constant (Study 2), and 3) unintentional injury-related infant mortality rates in West Virginia are significantly higher than national rates, stratified by race/ethnicity (Study 3).

During the 2010-2014 observation period, West Virginia documented 103,424 live births and 746 infant deaths. There were approximately 20 million live births and 118,000 infant deaths 
reported in the United States during the same period. Majority of infant deaths were associated with external causes of death were categorized as unintentional injury (28 deaths per 100,000 live births [Chapter 4, Figure 1 and 4]). Non-Hispanic Black infants accounted for approximately $3.5 \%$ of live births. White Non-Hispanic infants accounted for $93.5 \%$ of all live births and mean age of pregnancy was 26 years. Half of the mothers used Medicaid insurance during pregnancy, and half had a high school education or less. Approximately $62 \%$ of live births occurred in urban counties, even though approximately $51 \%$ of the West Virginian population reside in rural counties according to the U.S. Census Bureau.

\section{Study 1 discussion}

Injury-related infant death was associated with race/ethnicity, $\mathrm{p}=.0276$ and maternal smoking during pregnancy, $\mathrm{p}=.0003$. Therefore, the question that maternal and infant characteristics are associated with injury-related infant death was answered. The risk of a NonHispanic Black infant dying from injury-related causes was 4.0 (95\% CL: 1.7, 9.3) times the risk for infants from other races/ethnicities, holding other factors in the model constant. Previous research showed that Non-Hispanic Blacks were more likely than White Non-Hispanic counterparts to receive low-quality healthcare and to have a higher risk of hospital death following injury.[13,14] Consistent with previous literature, the risk of an infant dying from injury-related causes if the mother smoked during pregnancy was 2.9 (95\% CL 1.6, 5.0) times the risk if smoking status was unknown or the mother did not smoke, holding other factors in the model constant.

\section{Study 2 discussion}

Unintentional manner of injury was the major external cause of injury associated with injury-related infant death in West Virginia and in the U.S. Unintentional injury-related infant 
death was not strongly statistically related with rurality ( $\mathrm{p}$-value $=0.0905$ ). Thus, the hypothesis that relative risk of unintentional injury-related infant death is significantly higher in rural counties than in urban counties, holding other variables in the model constant was not supported. This finding was not unanticipated because past studies across the country and in Appalachia reported an association between infant mortality and rurality.[2,3,15-17] More investigation is needed using data with more proximal and distal characteristics in order to ascertain this findings.

\section{Study 3 discussion}

Although West Virginia is identified as rural,[18] its unintentional injury-related infant death mortality rate (UIIMR) is similar to that of the U.S, stratified by race/ethnicity. Hence the hypothesis that the UIIMR in West Virginia is significantly higher relative to the national rate, stratified by race/ethnicity was not confirmed. This could have been due to small sample sizes resulting in unstable confidence intervals. Nevertheless, the findings were unexpected since most characteristics that are associated with high rates of infant mortality rate (such as poverty and low levels of education) are pervasive in the state. Previous studies indicate that the age-adjusted UIIMRs in the U.S. population and rural areas have been rising,[19] and Womack and colleagues identified high infant mortality rural areas in the U.S.[15]

\section{Strengths and limitations}

Although injury-related infant death was associated with race/ethnicity and maternal smoking during pregnancy, thus corroborating past study findings. Lack of an association between the UIIM and rurality, holding other variables in the model constant, and lack of a significant difference between the UIIMRs in West Virginia and the national rates, stratified by race/ethnicity was surprisingly although it might be partially explained by data distribution and data limitations. Almost half of West Virginian pregnant women utilized Medicaid insurance 
during their pregnancy. According to past studies, Medicaid use during pregnancy protects against adverse perinatal outcomes.[4,8]

Several potential study limitations were identified. 1). The racial/ethnic distribution was skewed. Over $90 \%$ of the population were documented as White non-Hispanic. Past studies reported the IMR was similar or lower than the national IMR in this population. On the other hand, sparsity of the Non-Hispanic Black population in West Virginia induced data instability in the IMR, 2). Higher likelihood of misclassifications associated with medical coding errors, [20] 3) Complexity in forensic death investigations,[21] and 4) Information bias may also impact these data because they were originally collected for administrative purposes not for epidemiologic research.[22] Misclassification could either push the hypothesis test results towards or away from the null. The strength of the study is that this research is the only one using the proposed CDC external cause of death matrix to study unintentional injury-related infant deaths in West Virginia, as related to rurality.

\section{Future research}

While current community-based intervention programs seek to improve the overall quality of life in West Virginia, study findings highlight the need for re-engineering state- and community-based adverse health-related intervention approaches to meet the needs of the minority population and pregnant women in both rural and urban areas. Although current intervention programs encompass nurse home visitations, female education and policies, [23-27] they rarely, if at all, focus on the whole lifespan of women. Proponents of life course theory argue that health-related programs initiated in early life will benefit individuals throughout their lifetime. [28] Therefore, future research should employ life course theory in the assessment of unintentional injury-related infant mortally in West Virginia. 
Future research should also investigate the association of all household characteristics and injury-related infant deaths. This study could only access maternal and infant characteristics. Incorporating paternal characteristics might yield more information. Past studies identified an association between paternal characteristics and infant mortality.[29,30] Moreover, future research should aggregate data, especially when studying the relationship between injury-related death and rurality. Increasing the sample size, especially for minorities could stabilize the confidence intervals of the parameter estimates. Small sample size is associated with data instability.[31]

\section{Conclusions}

Non-Hispanic Black race/ethnicity, residence in rural counties, and maternal smoking during pregnancy emerged in this study as potential risk factors for injury-related infant death in West Virginia, information helpful to public health stakeholders involved in designing community-based interventions that can be deployed to assist in reducing such mortality. Even though the correlation between unintentional injury-related death among infants and rurality was weak, together with the relationship between unintentional injury-related death among infants and maternal smoking during pregnancy, it underscore the importance of continued expansion of community-based unintentional injury-related infant reduction programming targeted to pregnant women in both rural and urban counties who self-identify as smokers.

Stratified by race/ethnicity, the UIIMR was similar for West Virginia and the nation. However, this finding should be interpreted with caution because of the data instability reflected in the magnitude of the confidence interval. Further research is needed to investigate possible differences between the state and the nation using multi-year data to increase the number of cases. 


\section{References}

1. MacDorman MF, Matthews TJ, Mohangoo AD, Zeitlin J. International comparisons of infant mortality and related factors: United States and Europe, 2010. National vital statistics reports : from the Centers for Disease Control and Prevention, National Center for Health Statistics, National Vital Statistics System. 2014;63(5):1-6.

2. Spencer JC, Wheeler SB, Rotter JS, Holmes GM. Decomposing Mortality Disparities in Urban and Rural U.S. Counties. Health services research. 2018;53(6):4310-4331.

3. Mohamoud YA, Kirby RS, Ehrenthal DB. Poverty, urban-rural classification and term infant mortality: a population-based multilevel analysis. BMC pregnancy and childbirth. 2019;19(1):40.

4. Xaverius P, Alman C, Holtz L, Yarber L. Risk Factors Associated with Very Low Birth Weight in a Large Urban Area, Stratified by Adequacy of Prenatal Care. Maternal and child health journal. 2016;20(3):623-629.

5. Devoe JE, Baez A, Angier H, Krois L, Edlund C, Carney PA. Insurance + access not equal to health care: typology of barriers to health care access for low-income families. Ann Fam Med. 2007;5(6):511-518.

6. DeVoe JE, Krois L, Stenger R. Do children in rural areas still have different access to health care? Results from a statewide survey of Oregon's food stamp population. The Journal of rural health : official journal of the American Rural Health Association and the National Rural Health Care Association. 2009;25(1):1-7.

7. Gage TB, Fang F, O'Neill E, Dirienzo G. Maternal education, birth weight, and infant mortality in the United States. Demography. 2013;50(2):615-635. 
8. Johnelle Sparks P. One size does not fit all: an examination of low birthweight disparities among a diverse set of racial/ethnic groups. Maternal and child health journal. 2009;13(6):769-779.

9. Deputy NP, Sharma AJ, Kim SY, Hinkle SN. Prevalence and characteristics associated with gestational weight gain adequacy. Obstetrics and gynecology. 2015;125(4):773-781.

10. Hedderson MM, Gunderson EP, Ferrara A. Gestational weight gain and risk of gestational diabetes mellitus. Obstetrics and gynecology. 2010;115(3):597-604.

11. Deputy NP, Sharma AJ, Kim SY. Gestational Weight Gain - United States, 2012 and 2013. MMWR Morbidity and mortality weekly report. 2015;64(43):1215-1220.

12. Cheikh Ismail L, Bishop DC, Pang R, et al. Gestational weight gain standards based on women enrolled in the Fetal Growth Longitudinal Study of the INTERGROWTH-21st Project: a prospective longitudinal cohort study. Bmj. 2016;352:i555.

13. Arthur M, Hedges JR, Newgard CD, Diggs BS, Mullins RJ. Racial disparities in mortality among adults hospitalized after injury. Medical care. 2008;46(2):192-199.

14. Bernard SJ, Paulozzi LJ, Wallace DL, Centers for Disease C, Prevention. Fatal injuries among children by race and ethnicity--United States, 1999-2002. Morbidity and mortality weekly report Surveillance summaries. 2007;56(5):1-16.

15. Womack LS, Rossen LM, Hirai AH. Urban-Rural Infant Mortality Disparities by Race and Ethnicity and Cause of Death. American journal of preventive medicine. 2019.

16. Singh GK, Azuine RE, Siahpush M, Kogan MD. All-cause and cause-specific mortality among US youth: socioeconomic and rural-urban disparities and international patterns. 
Journal of urban health : bulletin of the New York Academy of Medicine. 2013;90(3):388-405.

17. Singh GK, Kogan MD, Slifkin RT. Widening Disparities In Infant Mortality And Life Expectancy Between Appalachia And The Rest Of The United States, 1990-2013. Health affairs. 2017;36(8):1423-1432.

18. The United States Census Bureau. West Virginia 2010 population and housing unit counts. Washington, DC: The United States Census Bureau;2012.

19. Olaisen RH, Rossen LM, Warner M, Anderson RN. Unintentional Injury Death Rates in Rural and Urban Areas: United States, 1999-2017. NCHS data brief. 2019(343):1-8.

20. McGivern L, Shulman L, Carney JK, Shapiro S, Bundock E. Death Certification Errors and the Effect on Mortality Statistics. Public health reports. 2017;132(6):669-675.

21. Byard RW, Shipstone RA, Young J. Continuing major inconsistencies in the classification of unexpected infant deaths. J Forensic Leg Med. 2019;64:20-22.

22. Northam S, Knapp TR. The reliability and validity of birth certificates. Journal of obstetric, gynecologic, and neonatal nursing : JOGNN. 2006;35(1):3-12.

23. Misra R, Fitch C, Roberts D, Wright D. Community-Based Diabetes Screening and Risk Assessment in Rural West Virginia. J Diabetes Res. 2016;2016:2456518.

24. O'Hara Tompkins N, Zizzi S, Zedosky L, Wright J, Vitullo E. School-based opportunities for physical activity in West Virginia public schools. Preventive medicine. 2004;39(4):834-840. 
25. Jack SM, Boyle M, McKee C, et al. Effect of Addition of an Intimate Partner Violence Intervention to a Nurse Home Visitation Program on Maternal Quality of Life: A Randomized Clinical Trial. Jama. 2019;321(16):1576-1585.

26. Jack SM, Ford-Gilboe M, Davidov D, MacMillan HL, Team NIR. Identification and assessment of intimate partner violence in nurse home visitation. J Clin Nurs. 2017;26(15-16):2215-2228.

27. Bhatia A, Krieger N, Subramanian SV. Learning From History About Reducing Infant Mortality: Contrasting the Centrality of Structural Interventions to Early 20th-Century Successes in the United States to Their Neglect in Current Global Initiatives. Milbank $Q$. 2019;97(1):285-345.

28. Lu MC, Kotelchuck M, Hogan V, Jones L, Wright K, Halfon N. Closing the Black-White gap in birth outcomes: a life-course approach. Ethn Dis. 2010;20(1 Suppl 2):S2-62-76.

29. Doamekpor LA, Amutah NN, Ramos LJ. Fathers matter: the role of paternal age in infant mortality. Am J Mens Health. 2014;8(2):175-182.

30. Ma S. Paternal race/ethnicity and birth outcomes. American journal of public health. 2008;98(12):2285-2292.

31. du Prel JB, Hommel G, Rohrig B, Blettner M. Confidence interval or p-value?: part 4 of a series on evaluation of scientific publications. Deutsches Arzteblatt international. 2009;106(19):335-339. 